\title{
Improving The Thermal Stability of 1-3 Piezoelectric Composite Transducers
}

\author{
A.C.S. Parr, R.L. O’Leary and G. Hayward \\ Centre for Ultrasonic Engineering, Dept. of Electronic and Electrical Engineering, University of \\ Strathclyde, 204 George Street, Glasgow G1 1XW, Scotland
}

\begin{abstract}
The effect of temperature on the behaviour of 1-3 piezoelectric composites manufactured using various polymeric materials was assessed experimentally through electrical impedance analysis and laser vibrometry. Device behaviour varied with temperature irrespective of the polymer filler. Most significant changes in the piezoelectric composites were recorded around the glass transition temperature $\left(\mathrm{T}_{\mathrm{g}}\right)$ of the polymer; movement to lower fundamental resonant frequencies and higher values of electrical impedance minima were observed at higher temperatures. Decoupling of the pillars from the polymer matrix was observed by laser vibrometry at high temperatures. The use of high $\mathrm{T}_{\mathrm{g}}$ polymer extended the operational temperature range of a piezoelectric composite and a high $\mathrm{T}_{\mathrm{g}}$ polymer with improved thermal conductivity also proved beneficial. For all devices, at temperatures very close to room temperature, subtle changes in device performance, linked to polymer softening, were observed. Particulate filled materials have been investigated and it is recognised that the high viscosities and low mechanical damping of such materials could be problematic for piezoelectric composite manufacture. Finally, the thermal solver of the PZFlex finite element code has been used to predict the temporal and spatial temperature response of a selection of the devices presented. The simulated and experimental data compare favourably.
\end{abstract}

\section{INTRODUCTION}

The management of unwanted thermal energy within piezoelectric composite devices is critical when considering such devices for a diverse array of applications. Such thermal energy can arise in the 
transducer structure itself as a result of high electrical drive power. Ideally, temperature increases occurring within a transducer as a result of mechanical and electrical losses should be minimised. In practice however, the temperatures reached by a device as a result of these losses and the effect of the temperature rise on the performance of the device, very much depend upon the exact configuration of the transducer and whether a heat sink, if available within the operational environment, can be used advantageously. Alternatively, extremes of temperature may be observed in the active transducer element as a result of the final application, for example in the acoustic probing of hostile environments. Probing environments with temperature as high as $700^{\circ} \mathrm{C}$ is currently of practical relevance. Essentially the performance of the transducer can be compromised as a result of extremes of temperature and it is important to consider such effects in the design process. In this paper the problems associated with elevated temperature in 1-3 piezoelectric composites will be considered. Essentially the passive phase is analysed and modified [1-9] to afford enhanced stability to the transducer subjected to increasing temperatures. Initially, preparation $[10,11]$ and characterisation of the elastic [9,12] and thermal properties [2,13-19] of a range of polymer materials was carried out, with particular emphasis on increasing both thermal conductivity and glass transition temperature $\left(\mathrm{T}_{\mathrm{g}}\right)$. Increasing the $\mathrm{T}_{\mathrm{g}}$ and the thermal conductivity of the polymer resin employed as the passive phase was expected to result in piezoelectric composite devices possessing improved thermal stability, particularly when a heat sink such as water is available during operation. Although some of the materials exhibit such characteristics, it was noted that increasing thermal conductivity of the host polymer by the addition of thermally conductive particles significantly affects the elastic nature of the cured resin. Indeed, a resin that is highly loaded with particulates tends to possess a very high viscosity in the uncured state $[4,6,7]$, thus rendering piezoelectric composite manufacture difficult and, 
therefore, a full practical assessment of the materials is necessary, prior to drawing any useful conclusions.

Assessment of the thermal behaviour of a number of piezoelectric composites prepared using this range of polymeric filler materials was then carried out. Particular emphasis is placed on the behaviour of the devices at temperatures in the region of the glass transition temperature of the polymeric filler. After assessing the thermal behaviour of piezoelectric composites manufactured using standard materials that have not been modified to impart enhanced thermal stability, methods of improving the thermal stability of piezoelectric composites were investigated through a combination of increasing thermal conductivity and $\mathrm{T}_{\mathrm{g}}$ of the polymer. Overall, a series of devices utilizing eight different polymeric materials has been investigated. In addition to three standard epoxy materials, ranging from rubbery through to hard compositions at room temperature, a polymer with a relatively high $\mathrm{T}_{\mathrm{g}}$ and four polymers containing thermally conductive particles were considered. Since the elastic character of the three standard materials ranges from hard to soft at room temperature the behaviour of the piezoelectric composites prepared using these materials should provide a very clear indication of the type of mechanical changes to be expected as the polymer undergoes significant thermal variation, i.e. as it passes from the hard glassy state to the soft rubbery state in the region of the $\mathrm{T}_{\mathrm{g}}$. Samples of 1-3 piezoelectric composites of $38 \%$ volume fraction were manufactured with each polymer as the passive phase. Electrical impedance measurements were conducted in an oven, as a function of device temperature and the observed device behaviour is compared with the measured polymer materials data. For more realistic assessment of the effects of induced temperature increases in the composite structure, a laser vibrometer system [20] was employed to measure surface displacement whilst the piezoelectric composite was subject to electrical drive. The variation in the surface dilation was monitored as the induced temperature was increased. Throughout the work the behaviour of the 
samples under the various test procedures were related to the measured characteristics of the polymer passive phase materials. From overall assessment of the behaviour of the different devices, methods of enhancing the thermal stability of piezoelectric composite transducers have been established.

Finally, analysis of the thermal behaviour of the composite structure is carried out using the thermal solver of the PZFlex finite element (FE) package [21]. For the success of such modelling, the detailed characterisation of the elastic and thermal properties of polymeric materials, as described in the early stages of the work, is crucial. In each case a 3D eighth symmetry unit cell model of the 1-3 connectivity composite is simulated. In order to simulate the response from the coupled electromechanical-thermal system, the PZFlex code monitors the losses in the transducer structure due to the mechanical damping that arise during the electromechanical portion of the problem. These mechanical losses are then converted into a thermal energy. The entire cycle of thermal generation, propagation and dissipation is simulated giving a temporal and spatial temperature response for the problem under consideration $[21,22]$. Losses occurring as a result of dielectric changes within the device have not been investigated here. The PZFlex FE code has been used to assess the thermal distribution of a number of the composites described in this paper, in each case the simulated and measured temperature response are shown to be in good agreement.

\section{POLYMER PREPARATION AND CHARACTERISATION}

Details of the eight epoxy-based thermosetting polymers under investigation are shown in Table 1. For the purposes of this work all materials were considered acoustically and thermally isotropic. To allow correlation of the behaviour of a 1-3 piezoelectric composite transducer with materials used to manufacture the device and to allow effective finite element modelling, high quality characterisation 
data is required. In order to assess the elastic properties of each of the materials under consideration, the longitudinal, $\mathrm{V}_{\mathrm{l}}$, and shear, $\mathrm{V}_{\mathrm{s}}$, acoustic wave velocities were measured by a through transmission time-of-flight technique $[9,12]$. This allows for the calculation of the salient elastic properties; Poisson's Ratio (v), Young's modulus (E), Shear modulus (G) and the specific acoustic impedance (Z) of each material. The attenuation of each wave type, $\alpha_{1}$ and $\alpha_{s}$ was also determined. The properties are sensitive to frequency and Table 2 details the velocity and attenuation of each wave type measured at $500 \mathrm{kHz}$ and the calculated mechanical properties. By consideration of the values measured for the standard materials, A, B and C in Table 2, it is apparent that increasing flexibility of the polymer at room temperature is reflected in reduced values of longitudinal and shear wave velocity and increasing values of attenuation. The flexibility of the material is, of course, a reflection of the modulus of the material, which when combined with the density of the material can be used to determine the velocity of a sample. Such changes in the elastic character are of importance when discussing the effect of temperature increases on the behaviour of 1-3 piezoelectric composite devices. Consider a device constructed from a polymer material, hard at room temperature and then rendered soft by an increase in temperature. As the polymer softens, similar behavioural characteristics may be anticipated, giving rise to real problems for designs based around, say a specific value of frequency and load impedance. Such effects are discussed more fully in the following sections.

The thermal behaviour of each of the polymer materials was assessed using a range of analytical techniques [13-17] and Table 3 details relevant values determined for each material. Polymers, as viscoelastic materials, have some of the characteristics of both viscous liquids and elastic solids. When a polymeric material is deformed, part of the energy is stored as elastic energy and part is dissipated as heat. The energy dissipated as heat manifests itself as damping or internal friction. Such effects can be probed during dynamic mechanical analysis [2,13]. As epoxy resins are polar in nature, molecular 
segments may have the ability to orient in an alternating electrical field. This effect can be assessed in dielectric studies where effects similar to those recorded during dynamic mechanical testing may be observed. Changes in dielectric behaviour have not been investigated to date. Dynamic mechanical thermal analysis (DMTA) was used to assess the $\mathrm{T}_{\mathrm{g}}$ (defined as the maximum value of $\tan \delta$ ) of each material using a Polymer Laboratories Mk III Dynamic Mechanical Thermal Analyser (DMTA), using single cantilever knife edge at $1 \mathrm{~Hz}$ with $\mathrm{x} 4$ strain and a torque setting of 40 . Samples $(25 \mathrm{~mm} \mathrm{x} 5 \mathrm{~mm} \mathrm{x}$ $2.5 \mathrm{~mm}$ ) were examined at a heating rate of $3^{\circ} \mathrm{Cmin}^{-1}$. A heating rate of $1{ }^{\circ} \mathrm{Cmin}^{-1}$ would result in a $\mathrm{T}_{\mathrm{g}}$ recorded at lower temperature [13]. The onset of molecular motion in a polymer sample can be recognised by changes observed in the storage modulus (E'), which quantifies amount of stored energy in the system and by changes in the loss modulus (E'), which quantifies the amount of energy dissipated by the material. From Table 3 it is clear that the properties of polymers A-C are reflected in the measured values of $\mathrm{T}_{\mathrm{g} .}$. Polymer $\mathrm{A}$ is hard at room temperature since it has $\mathrm{T}_{\mathrm{g}}$ greater than room temperature. Similarly, polymer $\mathrm{C}$ is flexible at room temperature, a fact that is reflected in the $\mathrm{T}_{\mathrm{g}}$ of $6^{\circ} \mathrm{C}$ for this material. When a material is added to a polymer, the extent of the interaction between the polymer and the additive can vary. In some cases the $T_{g}$ of the polymer can be increased. The filled polymers, $\mathrm{G}$ and $\mathrm{H}$, had similar $\mathrm{T}_{\mathrm{g}}$ values to the base polymer $\mathrm{D}$, all measured in the temperature range of $145-155^{\circ} \mathrm{C}$. The Stycast samples, $\mathrm{E}$ and $\mathrm{F}$, had $\mathrm{T}_{\mathrm{g}}$ values at measured at $87^{\circ} \mathrm{C}$ and $84^{\circ} \mathrm{C}$ respectively. The specific heat capacity $(\mathrm{Cp})$ of each polymer was determined using differential scanning calorimetry (DSC) $[14,15]$. A Dupont Mk IV Thermal Analyser was used to investigate the thermal behaviour of a sample of each polymer (10-20mg) and a sapphire standard sample (63mg) [16] using a heating rate of $10^{\circ} \mathrm{C} / \mathrm{min}$ and matched aluminium pans. In general the specific heat capacity increased as the temperature increased and Table 3 details the values of specific heat capacity for each material at $25^{\circ} \mathrm{C}$. Relatively high heat capacity values were calculated for polymers $\mathrm{B}$ and $\mathrm{C}$, 
the unloaded polymers which are more flexible at room temperature, compared to those calculated for polymers $\mathrm{A}$ and $\mathrm{D}$, materials which are more rigid at room temperature. In general, the polymers containing thermally conductive filler particles have lower heat capacity values than the unloaded polymer samples. The specific heat capacity of each of the particulate filler materials is reported to be around $0.6-0.9 \mathrm{~kJ} / \mathrm{kgK}[18,19]$ but the exact value is expected to depend on particular characteristics of the additive, for example, the purity of the material. From this information it was anticipated that the specific heat capacity of the polymer materials containing thermally conductive particles would be lower that that of unloaded polymer systems but values for each material were not predicted. Using Netzsch LFA427 instrumentation and a laser flash method [17], the thermal diffusivity $(\alpha)$ for each material was determined. A polymer disc, approximately $12 \mathrm{~mm}$ diameter and $500 \mu \mathrm{m}$ thick, was prepared. To prevent penetration of the laser beam, samples D, E, F and G were coated with graphite before testing. The thermal diffusivity was measured in an argon atmosphere by increasing the temperature at $5^{\circ} \mathrm{C} / \mathrm{min}$. From this, values for the thermal conductivity $(\mathrm{k})$ were calculated. The thermal diffusivity values decreased as the temperature was increased and a step decrease occurred at $\mathrm{T}_{\mathrm{g}}$. From Table 3 it is apparent that the measured value for the unfilled high $\mathrm{T}_{\mathrm{g}}$ polymer $\mathrm{D}$, compared well with the calculated value and the thermal diffusivity values measured at $25^{\circ} \mathrm{C}$ for $\mathrm{G}$ and $\mathrm{H}$, were higher than measured for D as would be expected. Measured thermal diffusivity values and heat capacity values were used to calculate thermal conductivity values for a number of the materials. It is generally recognised that the thermal conductivity of a polymer is increased as the concentration of the thermally conductive additive is increased [7]. As shown in Table 3, values calculated for polymer materials containing thermally conductive additive were higher than the values reported for the unfilled polymers, and, as would be expected, the calculated values were much lower than values reported for the pure additives. Measured values of $0.38 \mathrm{~W} / \mathrm{mK}$ and $1.05 \mathrm{~W} / \mathrm{mK}$ respectively were 
obtained for the thermal conductivity of Stycast samples E and F. The manufacturer's reported values were $0.5 \mathrm{~W} / \mathrm{mK}$ and $1.36 \mathrm{~W} / \mathrm{mK}$ respectively. In both cases, the measured value is lower but it should be noted that the latter were obtained using a different experimental procedure. Polymer F, which contains aluminium oxide, has a much higher thermal conductivity than each of the other filled polymer samples investigated. Interestingly, this high thermal conductivity value correlates well with the highest velocity values, the highest density value and the lowest longitudinal attenuation values as shown in Table 2, reinforcing the concept of high levels of additive being contained in this material. Very similar values of $0.38 \mathrm{~W} / \mathrm{mK}$ and $0.41 \mathrm{~W} / \mathrm{mK}$ respectively were calculated for the thermal conductivity at $25^{\circ} \mathrm{C}$ for materials $\mathrm{G}$ and $\mathrm{H}$. Although the thermal conductivity of aluminium nitride powder is reported to be much greater than the thermal conductivity of aluminium oxide, aluminium nitride was used at lower concentration than aluminium oxide and this could explain why the thermal conductivity of the aluminium nitride system $\mathrm{H}$ is not much higher than that measured for the aluminium oxide system $\mathrm{G}$.

\section{VARIATION OF ELECTRICAL IMPEDANCE AS A FUNCTION OF TEMPERATURE}

In order to practically assess the materials that were prepared and analysed in the initial stages of this paper, a range of piezoelectric composite devices was prepared. As detailed in Table 4, a piezoelectric composite device of $38 \%$ ceramic volume fraction PZT5A [23] was manufactured using each of the different polymers. Each device had three calibrated K-type thermocouples embedded in a common quadrant in the polymer kerf, at half the pillar height, to monitor internal temperature under practical drive conditions. Two 1-3 piezoelectric composites, devices A1 and A2, were manufactured from the standard hardest polymer A. For completeness, the details of each device have been included in Table 4 and the device examined during a particular experimental procedure discussed below has been 
specified but, generally, reproducible behaviour was observed and data collected from both devices can be considered representative of the behaviour of a 1-3 piezoelectric composite manufactured from the standard hardset polymer.

To investigate the effect of temperature changes on the electrical impedance magnitude of a 1-3 piezoelectric composite, the impedance spectrum of each device was recorded using a HP4194A impedance analyser, as a function of temperature. Each transducer was heated at a rate of approximately $2^{\circ} \mathrm{Cmin}^{-1}$ in an oven and the impedance response was recorded at $5^{\circ} \mathrm{C}$ intervals. The drive voltage applied to the transducer in this test, approximately $300 \mathrm{mV}$ peak-to-peak, was insufficient for the generation of measurable thermal effects within the device. Waterfall plots were produced to highlight the changes in device behaviour as the temperature was increased. The frequency and magnitude of the thickness mode impedance minimum (electrical resonance - $\mathrm{f}_{\mathrm{e}}$ ) and impedance maximum (mechanical resonance $-\mathrm{f}_{\mathrm{m}}$ ) were considered in detail.

Figures 1a-c show the effect of increasing temperature on the electrical impedance profile of devices $\mathrm{A} 1, \mathrm{~B}$ and $\mathrm{C}$ respectively. These devices were manufactured from the three standard polymers as detailed in Table 4. The reproducibility of the thermal behaviour measured for the 1-3 piezoelectric composites was demonstrated since the behaviour of a similar device (A2) compared well with the behaviour of device A1 and both devices were manufactured from the standard hardset polymer.

It is possible to consider the electrical impedance data used to produce the waterfall plots in much more detail so that the effect of temperature changes on particular aspects of 1-3 piezoelectric composite performance can be highlighted. Figures 2a-c depict the important changes recorded in the behaviour of device A1. The change in frequency of the fundamental thickness mode resonance 
impedance minimum $\left(f_{e}\right)$ and maximum $\left(f_{m}\right)$ are plotted in Figure 2a. The associated variation in impedance magnitude of $f_{e}$ and $f_{m}$ are shown in Figures $2 b$ and Figure 2c respectively, again similar behaviour was recorded for device A2.

The variations shown in Figures $2 \mathrm{a}-\mathrm{c}$ can be explained by considering the changes that are occurring in the composite as the temperature is increased. As the temperature increases, the polymer softens. From the characterisation data collected using ultrasonic through transmission, presented in Table 2 , it is known that the effective velocities decrease as the polymer becomes progressively softer. This causes the frequency of the electrical resonance and the mechanical resonance to decrease. These effects are apparent in Figures 2a. Simultaneously, the magnitude of the electrical impedance at the electrical resonance increases and the magnitude of the electrical impedance at the mechanical resonance decrease, both indicative of increased damping due to the increase in polymer attenuation. Eventually, as the polymer softens further, and enters into the glass transition regime, decoupling of the pillars occurs. Decoupling was experimentally verified using a scanning laser vibrometer, the pillars and the polymer in the 1-3 piezoelectric composite were observed to move independently. This effect is discussed in greater detail in Section IV; although the decoupling can be identified by consideration of Figures $2 \mathrm{~b}$ and $2 \mathrm{c}$. The onset of decoupling occurs just after the maximum of the impedance magnitude of $f_{e}$ and a minimum of the impedance magnitude of $f_{m}$, when losses in the polymer filler are maximised. For the devices comprising the hard polymer as the passive phase, this phenomenon was observed at approximately $100{ }^{\circ} \mathrm{C}$. An obvious corollary of these variations in the electrical impedance characteristic is the concurrent change in effective coupling coefficient $\left(\mathrm{k}_{\mathrm{t}}\right)$ and quality factor (Q) which passes through a minimum at $100^{\circ} \mathrm{C}$, the point of maximum loss. From Figure 2a it is apparent that a step increase in the frequency of both the electrical and the mechanical resonance 


\begin{abstract}
occurs as a result of decoupling in the 1-3 piezoelectric composite. The respective temperatures at which decoupling was observed in devices $\mathrm{B}$ and $\mathrm{C}$ were $45^{\circ} \mathrm{C}$ and $20^{\circ} \mathrm{C}$. Such behaviour is considered representative of the polymer in the piezoelectric composite passing through the region of $\mathrm{T}_{\mathrm{g}}$ and further comment will be made at the end of this section.
\end{abstract}

As noted previously, the temperature where maximum loss is recorded, marking the temperature of the onset of decoupling of a 1-3 piezoelectric composite, is important. However, the temperature which marks the initiation of the variation in electrical impedance occuring is also important and is related to the onset of polymer softening. From Figures $2 \mathrm{a}-\mathrm{c}$ it is apparent that changes in the frequency or the magnitude of the electrical or the mechanical resonance occur, for device $\mathrm{A} 1$ at approximately $30^{\circ} \mathrm{C}$. Similar behaviour was recorded for device A2. For devices B and C, changes in behaviour were recorded throughout the temperature range investigated, the effects of softening were recorded at $21^{\circ} \mathrm{C}$ and approximately $4^{\circ} \mathrm{C}$, respectively. These noted temperatures are well below the respective $\mathrm{T}_{\mathrm{g}}$ of the polymer, measured at $60^{\circ} \mathrm{C}, 40^{\circ} \mathrm{C}$ and $6^{\circ} \mathrm{C}$ for materials $\mathrm{A}, \mathrm{B}$ and $\mathrm{C}$, respectively.

From these waterfall plots it is apparent that changes do occur in the electrical impedance profile of a 1-3 piezoelectric composite as the temperature is increased. However, the temperature range where most dramatic changes are observed does vary, depending on the type of polymer contained in the device. Changes in behaviour for the device manufactured using the flexible polymer $\mathrm{C}$ were observed at lower temperatures than those recorded for the device manufactured from polymer B and at much lower temperatures than those recorded for the device manufactured from polymer A. This behaviour is similar to that recorded using DMTA and presented in Section II where dramatic changes in behaviour were observed for each polymer system within a critical temperature range. However, the temperature range of most dramatic changes in the impedance plots for the 1-3 piezoelectric composites does not correlate exactly, with the temperature range of dramatic change in the elastic 
properties of the polymer observed in the DMTA measurements. Similarly the temperatures representative of the onset of softening do not correlate exactly but are more indicative of when changes will appear in transducer performance. The behaviour does appear to be related, however, and it is linked to the conformational behaviour of the passive phase as a function of temperature.

In the 1-3 piezoelectric composite, subtle increases in loss are recorded at temperatures much lower than the temperature recorded for $\mathrm{T}_{\mathrm{g}}$. From consideration of results obtained during DMTA, the onset of softening of polymers $\mathrm{A}, \mathrm{B}$ and $\mathrm{C}$ occurred at temperatures much lower than the temperature recorded as the maximum of the $\tan \delta$, used here to define $T_{\mathrm{g}}$. Relatively small increases in the loss modulus of the polymer occurred, indicative of relatively small amounts of softening occurring in the polymer. It is possible that these relatively small changes in the mechanical properties of the polymer, occurring at temperatures below the $\mathrm{T}_{\mathrm{g}}$ are responsible for the variations in the electrical impedance characteristic that are observed at temperatures below the $\mathrm{T}_{\mathrm{g}}$ of the polymer.

From consideration of time temperature superposition procedures, the temperature measured for $\mathrm{T}_{\mathrm{g}}$ is expected to show an increase of $5 \mathrm{~K}$ to $8 \mathrm{~K}$ per tenfold increase of frequency $[1,2,13]$ and there is some evidence of such effects occurring here. DMTA examined the behaviour of the polymer at $1 \mathrm{~Hz}$ and higher frequencies were applied when the effect of temperature on the electrical impedance of the 1-3 piezoelectric composite was examined. For all devices, made from each of the materials, maximum loss, occurring in the region of $\mathrm{T}_{\mathrm{g}}$, was determined at a higher temperature when examining the electrical impedance of the device than the temperature measured for $\mathrm{T}_{\mathrm{g}}$ of the polymer using DMTA. Similarly, as a result of the effects of time temperature superposition, the temperature where subtle changes in the electrical impedance were recorded, are correspondingly higher during assessment of the electrical impedance than those measured at relatively low temperatures using DMTA. 
If a polymeric material is subjected to high frequency, high amplitude oscillation, the temperature is increased as the heat generated in a material is proportional to the square of the amplitude, to the frequency and to the loss modulus. From this information there is the potential to quantify the heat generated in a polymer under specific conditions and compare the heat generated in each material directly. Generally it is found that $\tan \delta$ and the loss modulus are very small at very low and very high frequency but detailed assessment of the heat generated in each polymeric material has not been considered to date. Additionally it is recognised that dipole mobility in a fully cured and crosslinked system is low but, similar to the effects observed in dynamic mechanical studies, subtle changes to the orientation of dipoles in the polymer when an alternating electrical field is applied could occur as a result of changes in temperature or frequency. Such behaviour has not yet been investigated.

PZT-5A is a soft ceramic. Here it is assumed that the behaviour observed occurs as a result of changes to the polymer and not changes to the PZT-5A ceramic material. Reproducible behaviour was recorded during repeated investigations carried out on the piezocomposites and this would not have been observed if permanent irreversible changes had occurred to the 1-3 materials. When considering the piezoelectric constant, polarisation and permittivity have a strong temperature dependence. A considerable increase in permittivity with increasing temperature results in a reduced voltage constant. These effects have not been considered in detail to date. It is suggested that thermally activated aging of the material is minimized by restricting usage temperatures to less than half of the Curie temperature, a temperature of $365^{\circ} \mathrm{C}$ for PZT5A. Predominantly, samples were examined at temperatures within this temperature range.

Thus, movement to lower fundamental resonant frequencies, higher values of electrical impedance minima and increased bandwidth changes were observed in piezoelectric composite transducers 
operating at higher temperatures, as a result of polymer softening and increased mechanical loss within the device. The results presented above quantify the reduction in performance of a 1-3 piezoelectric composite that occurs when a device is operated at elevated temperatures. Particularly in the region of the glass to rubber transition temperature $\left(T_{g}\right)$, the elastic properties of the polymer filler can vary widely with respect to temperature and such changes can be deleterious to the performance and operating range of piezoelectric composites. As a result of temperature fluctuation and the associated shift in polymer elastic properties, transducer characteristics such as bandwidth, electrical impedance, uniformity of surface displacement and efficiency can be altered. In high power applications where temperature increases are induced as a result of higher input voltage, the effect of temperature variation can be particularly problematic. To avoid such effects it is anticipated that use of a high glass transition temperature polymer filler, such as that employed in device D could be used to manufacture 1-3 piezoelectric composites for high power or high temperature applications.

To demonstrate the improved thermal stability of a device comprising a high $\mathrm{T}_{\mathrm{g}}$ polymer, device $\mathrm{D}$, as described in Table 4, was assessed experimentally following the same procedures as outlined previously. Again, the electrical impedance profile for device D was recorded as a function of temperature. Figure 3 shows a waterfall plot of the resultant data.

From Figure 3, device D appeared stable until $140^{\circ} \mathrm{C}$, maximum loss was recorded at $170^{\circ} \mathrm{C}$ and use of a high glass transition temperature polymer filler material appeared to have enhanced the temperature stability of the device. By increasing the temperature of maximum loss from $100^{\circ} \mathrm{C}$ to $170^{\circ} \mathrm{C}$, the operational temperature range of the 1-3 piezoelectric composite had been extended. Figures 4a-c 
depict the variation in the frequency of $f_{e}$ and $f_{m}$ and the impedance magnitude at $f_{e}$ and $f_{m}$ for device D. The behaviour of the device is discussed more thoroughly in Section IV. A detailed examination of the variation of frequency and magnitude of the thickness mode electrical and mechanical resonances indicated that subtle changes were occurring in the device at temperatures as low as $30^{\circ} \mathrm{C}$.

From Figure 4 it is apparent that changes in the frequency of the electrical resonance were measured at $30^{\circ} \mathrm{C}$. The changes in performance of device D observed at such low temperatures were disappointing. It had been anticipated that by manufacturing a 1-3 piezoelectric composite containing a polymer with a relatively high $\mathrm{T}_{\mathrm{g}}$ of $151^{\circ} \mathrm{C}$, in preference to using a polymer $\mathrm{A}$ with a $\mathrm{T}_{\mathrm{g}}$ of $60^{\circ} \mathrm{C}$, the temperature of onset of softening would be correspondingly increased to temperatures higher than $30^{\circ} \mathrm{C}$; this shows no improvement over the temperatures where onset of softening was recorded for devices A1 and A2. Reassessment of the DMTA plot obtained for polymer D did suggest that losses could be increasing in the polymer at temperatures close to room temperature. Although it is possible that these relatively low levels of softening contributed to the performance changes observed when examining the electrical impedance of device D across a range of temperatures, the low thermal conductivity of the polymer filler was also considered significant. The introduction of thermally conductive additive particles into a host polymer could potentially enhance the thermal stability of the passive phase polymer. To this end, polymers loaded with thermally conductive filler particles and the 1-3 piezoelectric composite devices manufactured from these polymers were next investigated.

The variation in the magnitude of the electrical impedance as a function of temperature for device $G$ is presented as a waterfall plot in Figure 5. This device demonstrated maximum loss at $180^{\circ} \mathrm{C}$, which 
was slightly higher than recorded for the unloaded high $\mathrm{T}_{\mathrm{g}}$ system $\mathrm{D}$. However, changes in the electrical impedance characteristic were again observed at low temperatures. As an observation, this particular design has an additional mode in the vicinity of the main thickness resonance. As thermocouples monitor the uniformity of device temperature, the heating rate was considered slow enough to ensure even heating of the device. A collection of devices of this form have not been made to investigate this effect in detail, however, it is suggested that the additional mode is an overtone of the transducer width resonance and, due to the relatively low loss in the high $\mathrm{T}_{\mathrm{g}}$ polymer it is sustained and is able to interact strongly with the fundamental thickness mode as the latter shifts with temperature. The coupling of the two modes is observed to vary as a function of temperature, particularly between $90^{\circ} \mathrm{C}$ and $150^{\circ} \mathrm{C}$. This additional mode was not so problematic in device $\mathrm{D}$ as the shear velocity is much higher in the loaded polymer. This illustrates a fundamental design requirement for unimodal operation at the desired thickness mode resonance.

A further device, denoted device $\mathrm{H}$ in Table 4, was prepared. Figure 6 depicts the variation in the magnitude of the electrical impedance as a function of temperature. This device demonstrated maximum loss at $190^{\circ} \mathrm{C}$, which was slightly higher than recorded for device G. Figures 7a-c illustrate the changes in the frequency and magnitude of the electrical and mechanical resonances recorded for this device. Interference from overtones of the transducer width mode was not a problem because of the lower velocity values in polymer $\mathrm{H}$. A good balance of properties were measured for device $\mathrm{H}$, and although this device did not show absolute thermal stability because changes were observed in the frequency and magnitude of the electrical and mechanical resonance, it is anticipated that the presence of a thermally conductive additive in the material will prove advantageous during practical testing of devices. It is envisaged that the presence of the thermally conductive particles will allow greater and more rapid heat dissipation from the transducer, particularly when operating into a water load and this 


\begin{abstract}
would prevent deleterious temperature increases. The success of thermally conductive polymer materials would involve heat dissipation studies into water where the enhanced thermal conductivity of the polymer filler would act as an effective thermal pathway into a thermally dissipative load medium. The potential for greater enhancement of the thermal stability of such a system by further increasing the thermal conductivity of the polymeric filler material would be of interest as future work.
\end{abstract}

Device E demonstrated maximum loss at $130^{\circ} \mathrm{C}$, devices manufactured from this polymer, therefore, have a smaller operation temperature range than devices manufactured from the high $T_{g}$ polymer $D$ and each of the other polymers, F, G and $\mathrm{H}$, containing thermally conductive particles. For device $\mathrm{F}$, maximum loss was recorded at $170^{\circ} \mathrm{C}$. Again, an overtone from the transducer width mode was observed in the vicinity of the main thickness resonance. From Table 2 it is known that polymer F has relatively high longitudinal and shear velocity values, low Poisson's ratio and very low longitudinal and shear attenuation values as a result of high concentration of thermally conductive additive in the polymer. Low levels of mechanical damping occur in device $\mathrm{F}$ and interference from unwanted modes in the 1-3 piezoelectric composite could be problematic.

\title{
IV. Surface Displacement Profile AsSessment using Laser Vibrometry
}

For effective performance as an ultrasonic transducer, a 1-3 piezoelectric composite should exhibit uniform, piston-like surface displacement. A laser vibrometer system [20] can be used to probe the surface dilation of the transducer front face. In previous research carried out by the group [24], only a single frequency was investigated due to limitations on the laser vibrometer system. In this work, a Polytec Scanning Laser Vibrometer Model PSV300 [25] was used to measure the surface dilation as a 
function of temperature across a range of frequencies. The Polytec PSV300 is capable of rapidly scanning an area of the front face of a transducer to measure the surface displacement. To monitor the variation in surface displacement as a function of device temperature, an area encompassing 9 pillars, arranged in a $3 \times 3$ matrix, was investigated. The images recorded were considered representative of the behaviour of the complete device. Temperature increases were induced in the transducer by controlling the drive voltage applied across the transducer at a particular frequency and surface displacement was assessed at a range of different electrical input powers and at a range of different frequencies. Compared to using an oven to heat the 1-3 piezoelectric composite externally, it was assumed that inducing temperature increases in this manner was more representative of the realistic temperature increases that would be achieved in a device during operation, particularly under high power conditions. Using the embedded thermocouples to monitor the transducer temperature, surface displacement scans were recorded at $10^{\circ} \mathrm{C}$ intervals. The behaviour of devices $\mathrm{A} 2$ and $\mathrm{D}$ was examined.

Figure 8a-d demonstrates the effect of induced temperature increases on device A2. In Figures 8a and $8 \mathrm{~b}$, the magnitude and phase of the surface displacement of a $3 \times 3$ array of pillars are shown at $28^{\circ} \mathrm{C}$. A relatively uniform displacement of the order of $+/-10 \mathrm{~nm}$ is recorded and the motion of the polymer and the ceramic is in phase. However, considering the same array of pillars at $100^{\circ} \mathrm{C}$, as shown in Figures $8 \mathrm{c}$ and $8 \mathrm{~d}$, the ceramic displacement is dominant and moreover, the ceramic and the polymer are vibrating with a motion which is almost anti-phase. At $100^{\circ} \mathrm{C}$, the displacement of the ceramic is of the order of $+/-40 \mathrm{~nm}$, the displacement of the polymer is of the order of $+/-25 \mathrm{~nm}$ and the difference in phase angle between the ceramic and the polymer is approximately $145^{\circ}$. Importantly, these images illustrate the change in surface displacement that occurs when decoupling has started in a 1-3 piezoelectric composite as a result of induced temperature increases. The dramatic changes apparent in 
the images graphically explain why the performance of a 1-3 piezoelectric composite is so significantly influenced by temperature changes in the device. These images also clearly illustrate how surface displacement and, therefore, the overall performance of a 1-3 piezoelectric composite is influenced by the rigidity or the flexibility of the polymeric filler material in the device. The images in Figure $8 \mathrm{a}$ and $8 \mathrm{~b}$ are almost ideal and reflect the behaviour observed when the polymer in the 1-3 piezoelectric composite is rigid as occurs at temperatures below the $\mathrm{T}_{\mathrm{g}}$ of the material

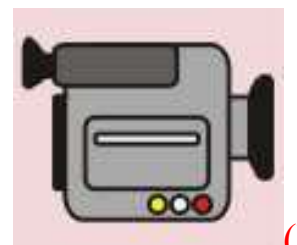

(Media-Movie 1) and the images in Figures $8 \mathrm{c}$ and $8 \mathrm{~d}$ are representative of the behaviour observed when the polymer in the 1-3 piezoelectric composite is soft and flexible as occurs

at temperature above the $\mathrm{T}_{\mathrm{g}}$ of the material

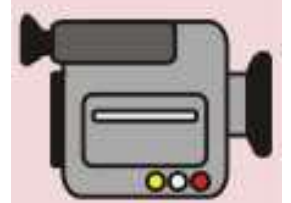
suggest that Figures $8 \mathrm{c}$ and $8 \mathrm{~d}$ reflect the behaviour expected for a 1-3 piezoelectric composite manufactured from any polymer that is inherently soft or flexible. Anti-phase behaviour in 1-3 piezoelectric composite transducers manufactured from flexible materials has been recognised for some time [26] and these images demonstrate this effect very well. The incorporation of a high glass transition temperature polymer filler material into a 1-3 piezoelectric composite was investigated with a view to avoiding such effects over a wider temperature range.

Detailed investigation of the magnitude of the surface displacement recorded at different temperatures and at a range of frequencies was also possible using the scanning laser vibrometer. From examination of both device A2 and device D it was noted that the frequency of maximum surface displacement was 
recorded at lower frequencies as the temperature increased. These results are similar to the behaviour discussed previously in Section III. Figure 9 depicts the variation in the frequency of maximum surface displacement as a function of temperature, for convenience the variation in the frequency impedance minimum obtained from the oven testing is reproduced on this figure. Figures $9 \mathrm{a}$ and $9 \mathrm{~b}$ depict the variation in frequency of maximum surface displacement for devices A2 and D, respectively.

The results of the oven and laser tests compare well, although the onset of decoupling appears to occur at a higher temperature in the data measured for device A2 using the laser vibrometer shown in Figures 9a. Importantly, however, in these investigations using the scanning laser vibrometer, the performance of both device A2 and device D begins to deviate from that recorded at room temperature with only very small increases in operating temperature. This behaviour was also recorded in the oven tests, and such effects were discussed in detail in Section III. As the data collected using the scanning laser vibrometer compared well with oven electrical impedance data, it was established that the test procedures described in this paper represent well the effect of temperature changes on the behaviour of a 1-3 piezoelectric composite. In addition the procedures are sensitive enough to be used easily to detect thermal stability in such devices.

\section{PZFlex Thermal ANAlysis}

In order to further analyse the thermal behaviour of the 1-3 connectivity composite structure and simulate power losses, the thermal solver of the PZFlex finite element package was employed [21]. To facilitate the modelling the thermal and elastic properties of each of the polymer materials that are to be simulated are required for the construction of the finite element model. All the necessary materials 


\begin{abstract}
characterisation data is reported in Section II. The FE model was used to predict the temperature rise of a selection of the piezoelectric composites detailed in Table 4. In each case the device was represented by three-dimensional eighth symmetry unit cell model surrounded by air. The changes in load impedance of each device and the variation in the mechanical properties of the constituents as a function of induced temperature were not taken into account in the FE model. Therefore this is not an exact solution however it is considered to be a suitable approximation. A fully coupled solution that did consider these changes would become unwieldy. The temperature profile in each model was recorded at the position of the thermocouple; i.e. at the centre of the kerf at half the device height.
\end{abstract}

The experimental temperature response of each device was measured by applying a continuous wave driving function across each device for 120 seconds. The temperature rise was recorded using the embedded thermocouple at 5-second intervals. Previous experimentation had confirmed that it was possible to induce temperature increases in a transducer by controlling the electrical input voltage into a system at a particular frequency. For each condition the input signal produced by the signal generator was kept constant. By recording the electrical input voltage, current and phase difference it was possible to calculate the average rate of energy dissipation for the alternating current signal applied. Previous experimentation had confirmed that subtle changes recorded in the measured voltage, current and time difference, over a five minute period, can occur depending on the severity of the set operating conditions, a result of the losses and the changes in the system as discussed previously. However, these subtle changes over the time periods of the experiments did not dramatically change the average power calculated for the conditions. Therefore, measurements made at the start of the experiment were typical of the conditions, set as a particular input at the start of the experiment and maintained throughout the experimental time period. Values used in the calculation of the average power were specifically measured for experimentation in an air or water test environment and therefore changes 
resulting from the different load on the front face of the transducer were taken into account during the analysis.

Figure 10(a) shows the theoretical and experimental temperature response for device A1 for an average power dissipation of 7.4W. It is clear from Figure 10(a) that there is an excellent correlation between theory and experiment for the air-backed device operating into an air load.

Figure 10(b) shows the same comparison for device B under the same mechanical load conditions, where the transducer drive conditions were equivalent to $3.4 \mathrm{~W}$ power dissipation. Again, good correlation is shown between the experiment measured and the theoretically determined temperature response of device B. Moving on to consider a device manufactured from a high $\mathrm{T}_{\mathrm{g}}$ polymer containing thermally conductive particles, Figure 11(a) shows the comparison between the theoretical and experimental temperature response for device G. In this example the transducer is air-backed and is operating into an air load, the average power dissipation is lower than the previous examples at $0.4 \mathrm{~W}$, a result of using less severe operating conditions, with a drive voltage of $22 \mathrm{~V}$ recorded in air. Again, the theory and experiment compare favourably. It was noted earlier that the use of the thermally conductive polymer system would be beneficial where the piezoelectric composite device is operating into a water load. The increased thermal conductivity should improve the dissipation of the heat into the water load. Figure 11(b) depicts the comparison between theory and experiment for device $\mathrm{G}$ where the front face is water loaded and the average power dissipation is $0.4 \mathrm{~W}$ with $34 \mathrm{~V}$ recorded. As was shown previously, the PZFlex model has accurately predicted the temperature rise in the device when operating into the water load. It is important to note that the final temperature rise is less than $1^{\circ} \mathrm{C}$ after 120 s excitation, where in the air loaded case a temperature rise of approximately $5^{\circ} \mathrm{C}$ was observed after 120 s excitation for the same average power dissipation. 
It is clear then that the finite element model has accurately represented the thermal behaviour of these devices. This is not an insignificant task and has required the accurate characterisation of the elastic properties of the materials under consideration, detailed in Section II. In particular, it reflects that the mechanical attenuation data of both the longitudinal and shear wave types is accurate since it is from this mechanical loss data that the FE code predicts the thermal response of the device. In addition, the measurement of the thermal properties of each of the materials, also presented in Section II was also indispensable to the FE analysis of the piezoelectric composite devices that has been presented.

\section{Conclusions}

The behaviour of piezoelectric composite transducers was found to vary significantly with temperature, irrespective of the passive phase contained in the device. As the temperature of the piezoelectric composite was increased movement to lower fundamental resonant frequencies and higher values of electrical impedance minima were observed as a result of polymer softening and increased mechanical loss within the device. The device passes through a region of maximum loss where the fundamental thickness mode resonance is highly damped. As the temperature is increased further, resonant behaviour is again evident in the electrical impedance characteristic; it has been proposed that this is a result of decoupling of the pillars of the composite from the polymer matrix as the temperature is increased. The decoupling within a piezoelectric composite at elevated temperature has been experimentally verified using a scanning laser vibrometry system. In addition, laser vibrometry has been used to monitor the frequency of maximum relative surface displacement of a selection of piezoelectric composites as a function of temperature. The variation of the frequency of maximum relative surface displacements as a function of temperature has been shown to be similar to the variation in $\mathrm{f}_{\mathrm{e}}$ observed from the electrical impedance characteristic. 
Using a combination of these two techniques to monitor device behaviour, and hence polymer softening, it has been shown that, irrespective of the polymer employed in the piezoelectric composite, softening occurred at temperatures below the measured $T_{g}$ for the polymer material in question. Indeed, in some cases significant softening of the polymer matrix leading to a deviation in the behaviour of the device was observed for only very small increases in temperature. It is argued that this polymer softening is related to the subtle changes in the elastic properties that were recorded using DMTA. Such behaviour stressed the importance of minimising or avoiding induced temperature increases and highlights requirement to analyse a polymer resin in more detail than measuring the value of $T_{g}$ when manufacturing a device for elevated temperature applications. Although the use of a high $\mathrm{T}_{\mathrm{g}}$ polymer did extended the operational temperature range of a piezoelectric composite, again the onset of softening, leading to variation in device behaviour, was observed for very small increases in temperature.

The addition of thermally conductive particles in the formulation has demonstrated the potential to increase the thermal conductivity of the passive polymer phase and increase the heat dissipation from the device. Indeed, device $\mathrm{H}$, comprising an aluminium nitride filled polymer matrix, exhibited improved temperature stability over the non conductive counterpart. Where a high level of thermally conductive additive is included in the polymer matrix, for example that in device F, the elastic nature of the material can lead to spurious modes being sustained in the composite structure and interfered with the fundamental thickness mode resonance. In addition the high level of additive will lead to the resin being highly viscous in the uncured state leading to problems in the filling of bristle blocks in composite manufacture. 
Aided by accurate polymer characterisation data, the thermal solver of the PZFlex finite element code has been used successfully to predict the temporal and spatial temperature response of a selection of the devices presented. The quality of the correlation is credited to the extensive characterisation of both the elastic and thermal properties of the materials presented in Section II of this paper. It has also highlighted the enhanced thermal diffusivity that can be afforded to the composite structure by enhancing the thermal conductivity of the passive polymer phase giving an improved thermal pathway for the dissipation of unwanted thermal energy, particularly to liquid load media. It is proposed that the FE method will be of benefit for the design of thermally active front face layers that can efficiently remove thermal energy from the composite structure to the load medium. This topic will form the subject of a subsequent publication. In addition, further polymer formulations will be considered, varying the type and level of thermally active additive and the practical assessment of piezoelectric device operating into a water load will also be undertaken.

\section{REFERENCES}

1. T.R. Gururaja, W.A. Schulze, L.E. Cross, R.E. Newnham, B.A. Auld and Y.J. Wang. "Piezoelectric Composite Materials for Ultrasonic Transducer Applications. Part 1: Resonant Modes of Vibration of PZT Rod-Polymer Composites", IEEE Transactions on Sonics and Ultrasonics, Vol SU-32 (4) 481-498, (1985).

2. J.M.G. Cowie, "Polymers: Chemistry and Physics of Modern Materials", Intertext books, London (1973).

3. W.G. Potter, “Epoxide Resins”, Plastics Institute, Illiffe Books, London, (1970).

4. C.A. May (Ed), "Epoxy Resins-Chemistry and Technology" Ed 2, Marcel Dekker New York, (1988). 
5. M.T. Goosey (Ed), "Plastics for Electronics”, Elsevier, London, (1985).

6. J. Wu, S. Bhattacharya, C. Lloyd, C.P. Wong, H.B. Pogge and R.R. Tummala, "Development of High Performance Interfill Materials for System Chips Technology", IEEE Transactions on Components and Packaging Technologies, 25 (2), 217-223, (2002).

7. J.W. Bae, W. Kim, S.K. Cho and S.H. Lee, "The Properties of AlN-filled Epoxy Molding Compounds by the Effects of Filler Size Distribution”, Journal of Materials Science, 35, 59075913, (2000).

8. R.L. O'Leary and G. Hayward, “Investigation into the Effects of Modification of the Passive Phase for Improved Manufacture of 1-3 Connectivity Piezocomposite Transducers”, IEEE Transactions on Ultrasonics, Ferroelectrics and Frequency Control, 46 (3), 511-516, (1999).

9. R.L. O'Leary, 'An Investigation into the Passive Materials Utilised within the Construction of Piezoelectric Composite Transducers', Ph D Thesis, University of Strathclyde, Glasgow, Scotland, (2003).

10. Cold Curing Araldite Resin Systems, Huntsman (previously Ciba Polymers/Vantico), Duxford, Cambridge, CB2 4QA, U.K.

11. Stycast Product Literature, Emerson and Cuming Speciality Polymers, London, NW10 7PN, U.K.

12. H.J. McSkimmin, Ultrasonic Methods for Measuring the Mechanical Properties of Solids and Liquids', Physical Acoustics, Vol. 1 Part A. Ed. W.P. Mason, Academic Press, London, (1964).

13. Standard Test Method for Assignment of the Glass Transition Temperature by Dynamic Mechanical Analysis ASTM E-1640 (1999).

14. M.J. O’Neill, "Measurement of Specific Heat Functions by Differential Scanning Calorimetry", Analytical Chemistry, 38, 1331-1336, (1966). 
15. J.L. McNaughton and C.T. Mortimer. "Differential Scanning Calorimetry" Perkin Elmer Corporation, Norwalk, Conneticut 06856, USA.

16. D.C. Ginnings and G.T. Furukawa, "Heat Capacity Standards for the range 14-1200K" J. Amer. Chem. Soc. 75, 522-527 (1953).

17. G. Braeuer, L. Dusza, and B.Schulz. "New Laserflash Equipment LAFA427”, Interceram, 41, 7/8 489-492, (1992).

18. The Merck Index, An Encyclopedia of Chemicals, Drugs and Biologicals, $13^{\text {th }}$ Edition, Merck and Co Inc, Whitehouse Station, N.J. (2001).

19. Goodfellow Product Literature, Ermine Business Park, Huntingdon, Cambridgeshire, England, PE29 6WR.

20. P. Reynolds, “Analysis and Design of Piezocomposite Ultrasonic Transducers using Finite Element Technique and Surface Displacement Profiles", Ph.D. Thesis, University of Strathclyde, Glasgow, Scotland, (1998).

21. PZFlex Users Manual, Wiedlinger Associates, 4410 El Camino Real, Suite 110, Los Altos CA 94022.

22. Abboud, N., Mould, J., Wojcik, G., Vaughan, D., Powell, D., Murray, V. and MacLean, C., 'Thermal generation, diffusion and dissipation in 1-3 piezocomposite sonar transducers: finite element analysis and experimental measurements' Proceedings of 1997 IEEE Ultrasonics Symposium, pp895-900, 1997.

23. Morgan Advanced Ceramics, Bewdley Road Stowport on Severn, Worcestershire, UK. DY13 8QR.

24. A.C.S. Parr, R.L. O’Leary, G. Hayward, G. Smillie, A. Rice and P.T. Smith. 'Experimental and Theoretical Evaluation of the Thermal Behaviour of 1-3 Piezoelectric Composite Transducers' 
Proc. IEEE International Ultrasonics Symposium pp. 1041-1044, Puerto Rico, 22-25 October, (2000).

25. Lambda Photometric Limited, Lambda House, Batford Mill Harpenden, Hertfordshire AL5 5BZ, UK.

26. W.A. Smith, "Optimising Electromechanical Coupling in Piezocomposites using Polymers with Negative Poisson’s Ratio” IEEE Ultrasonics Symposium Proceedings, 661-666, (1991). 




Figure 1(a) 


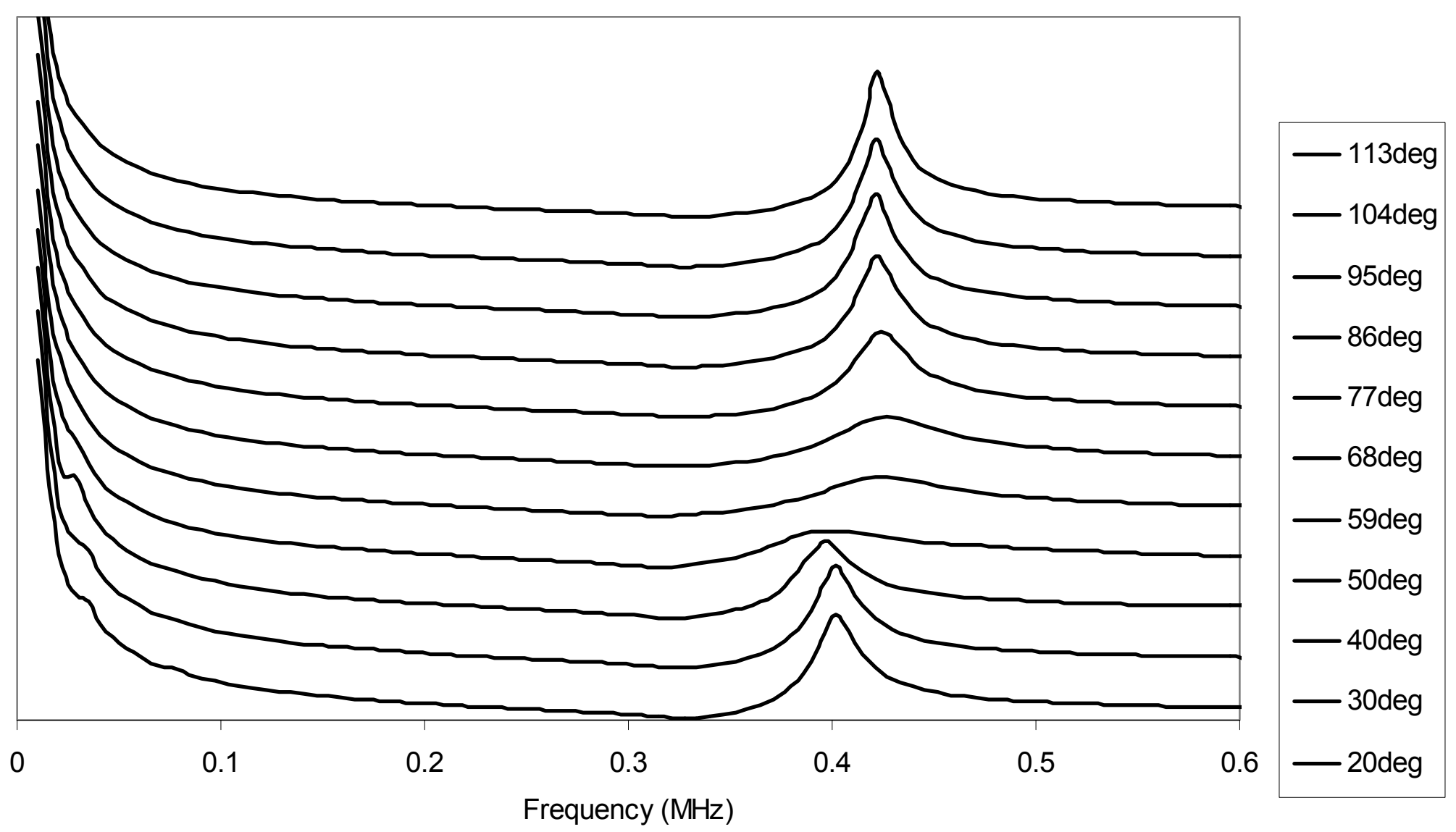

Figure 1(b) 


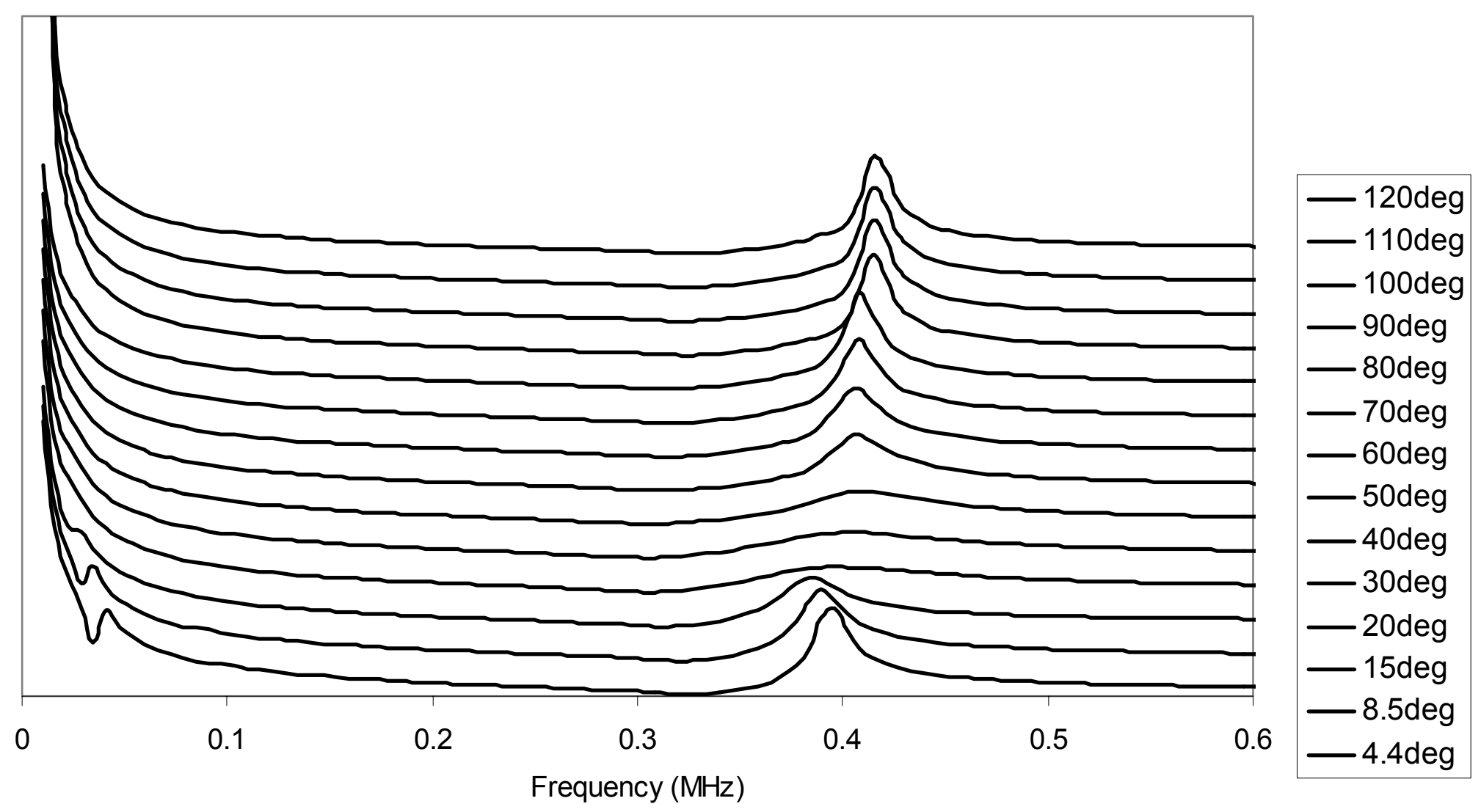

Figure 1(c) 


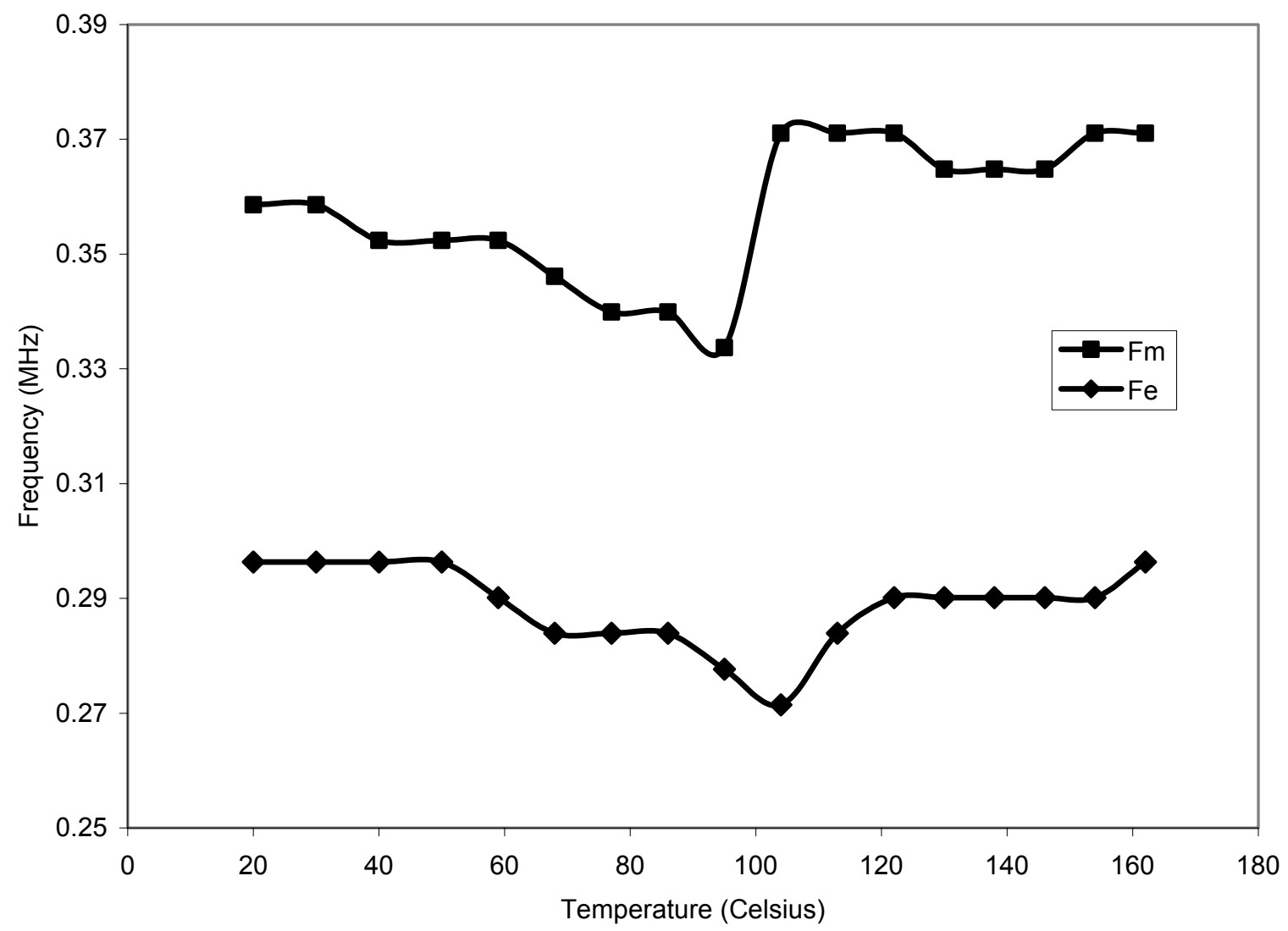

Figure 2(a) 


\section{Page 33 of 56}

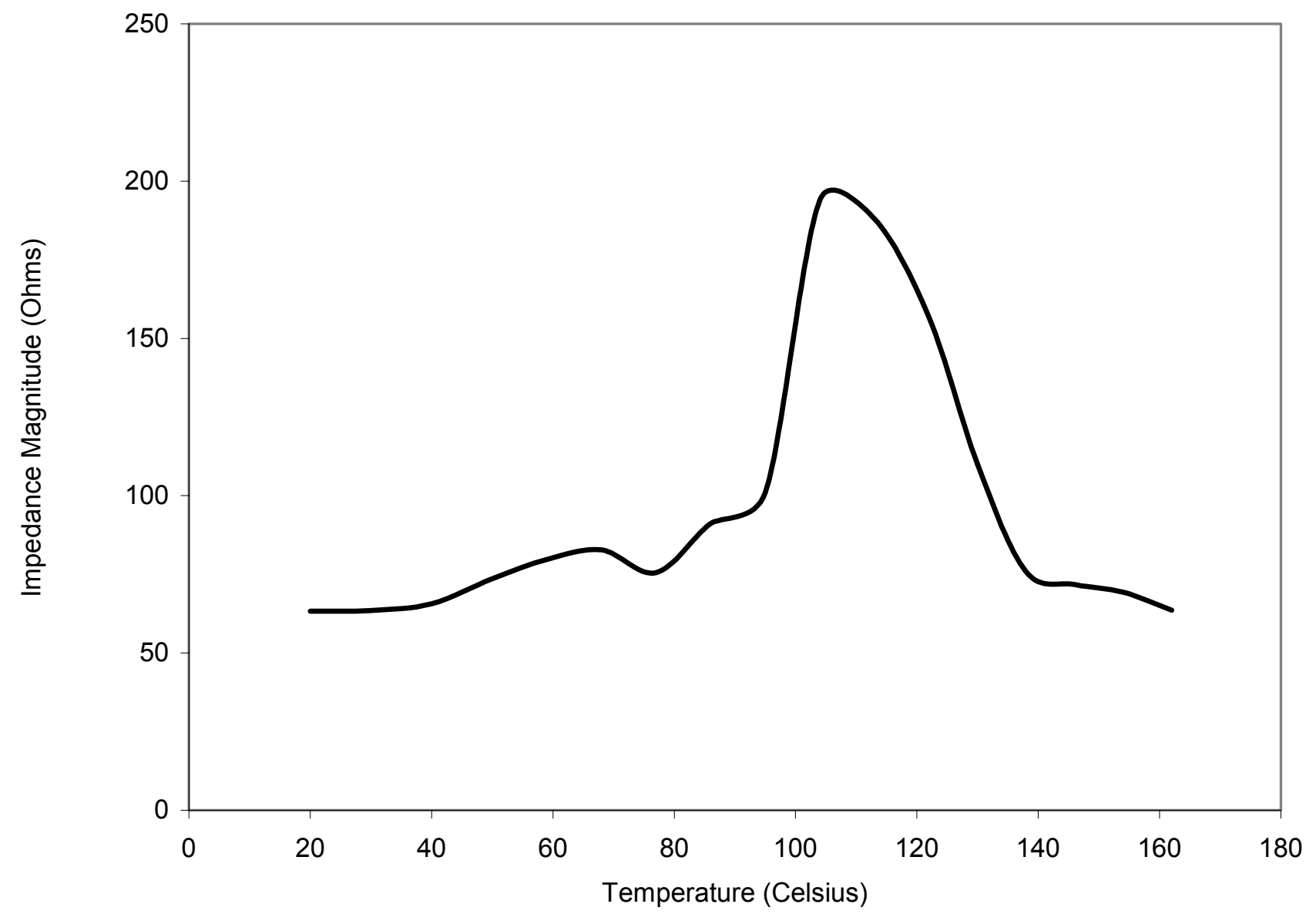

Figure 2(b) 


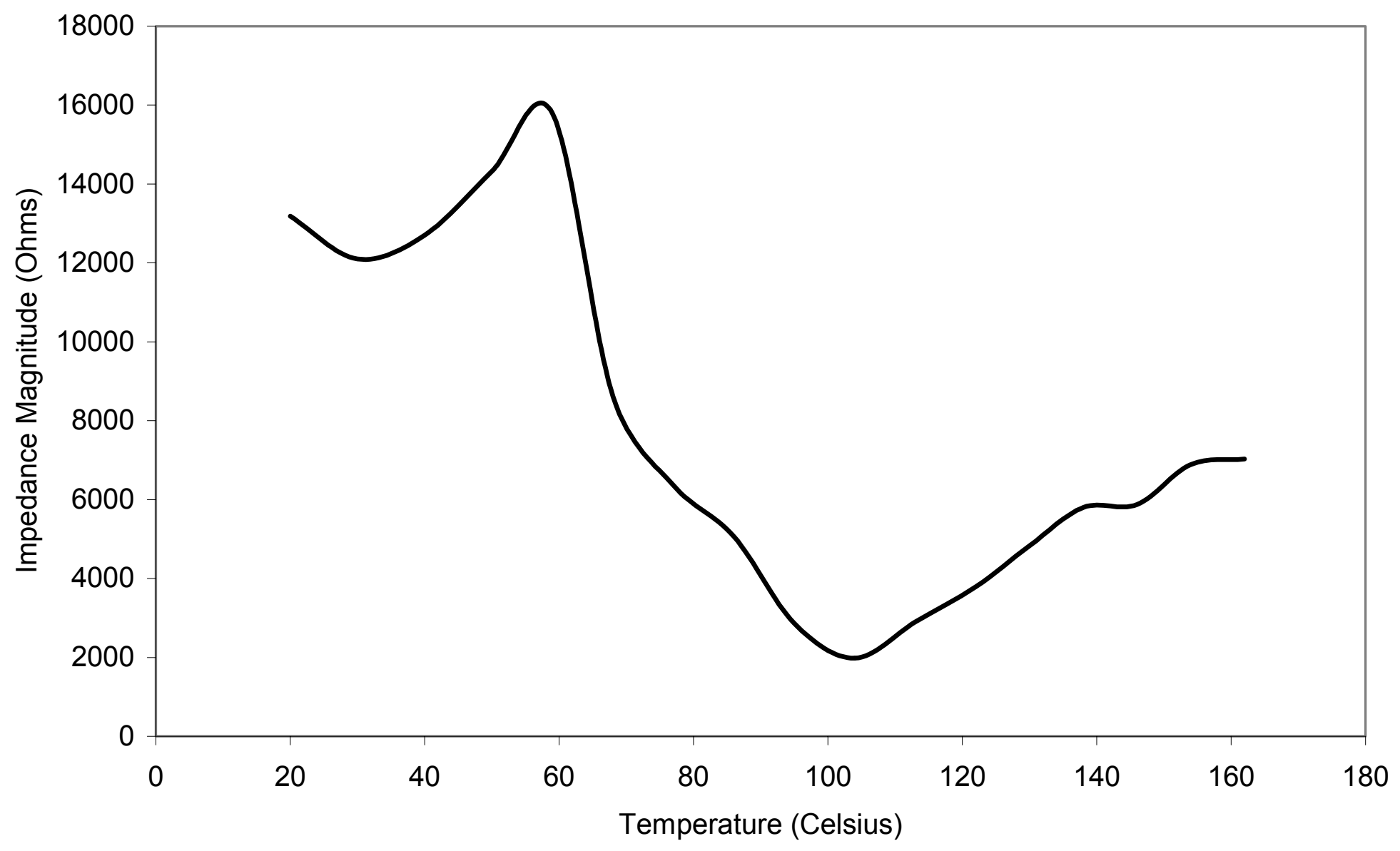

Figure 2(c) 


\section{Page 35 of 56}

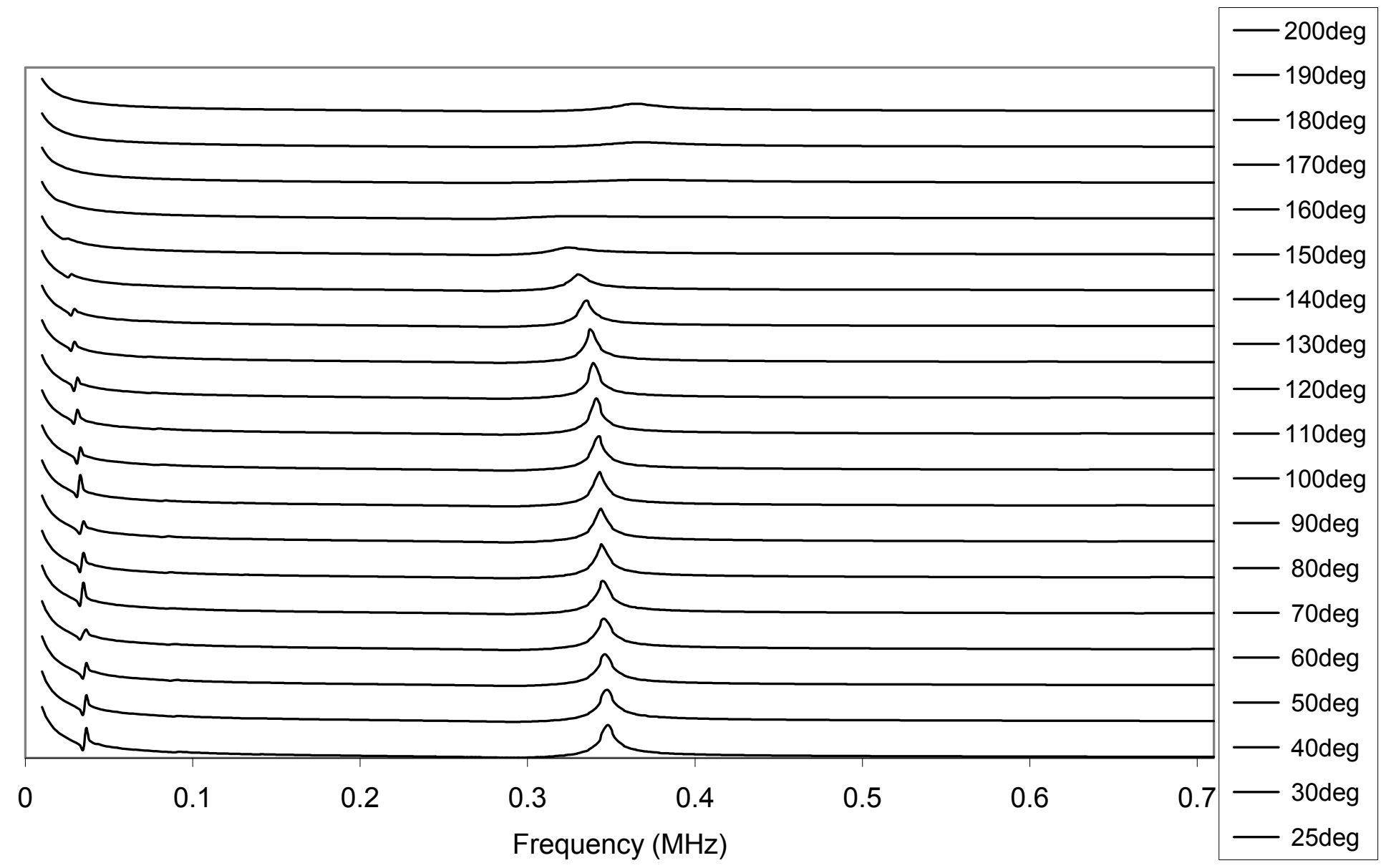

Figure 3 


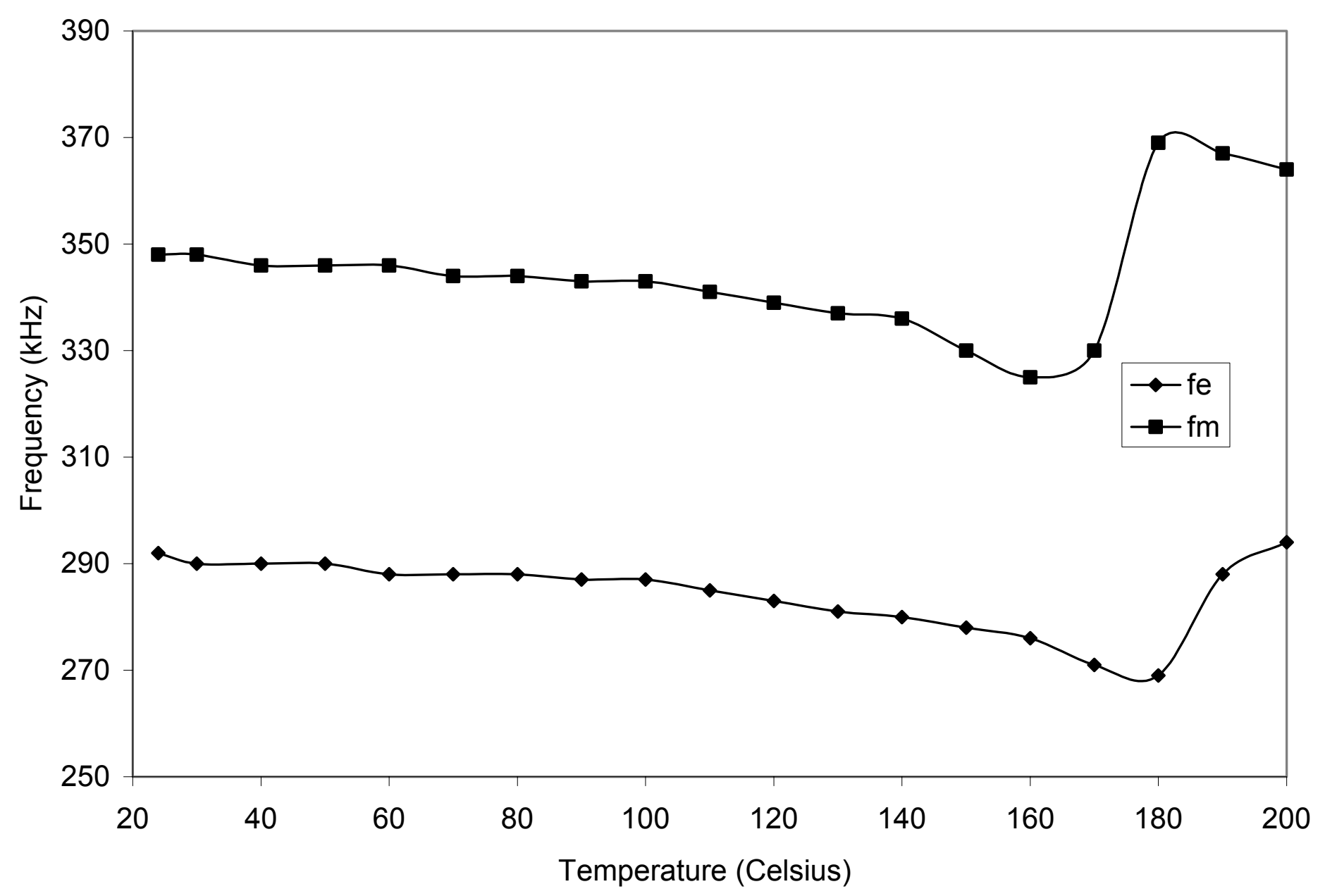

Figure 4(a) 


\section{Page 37 of 56}

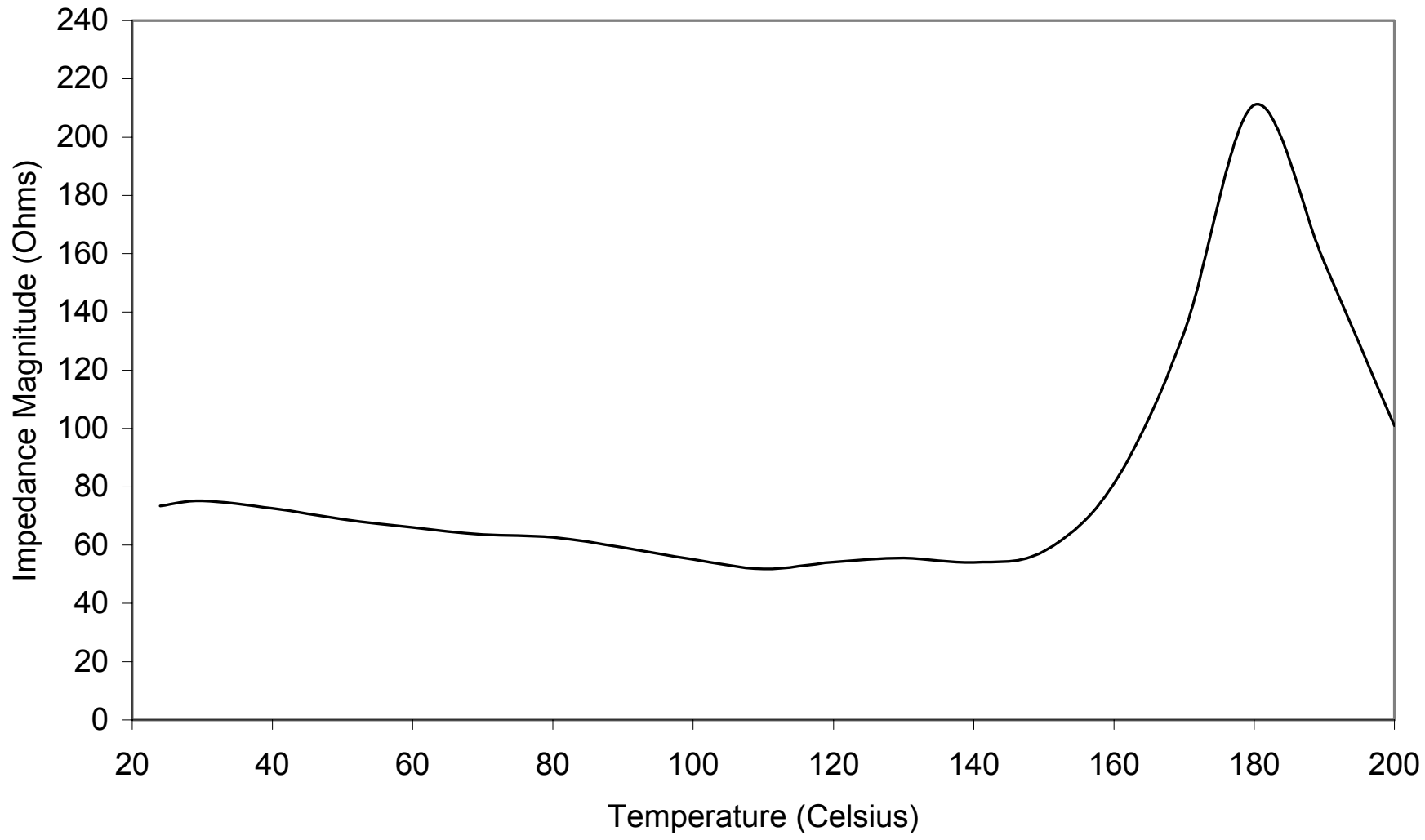

Figure 4(b) 


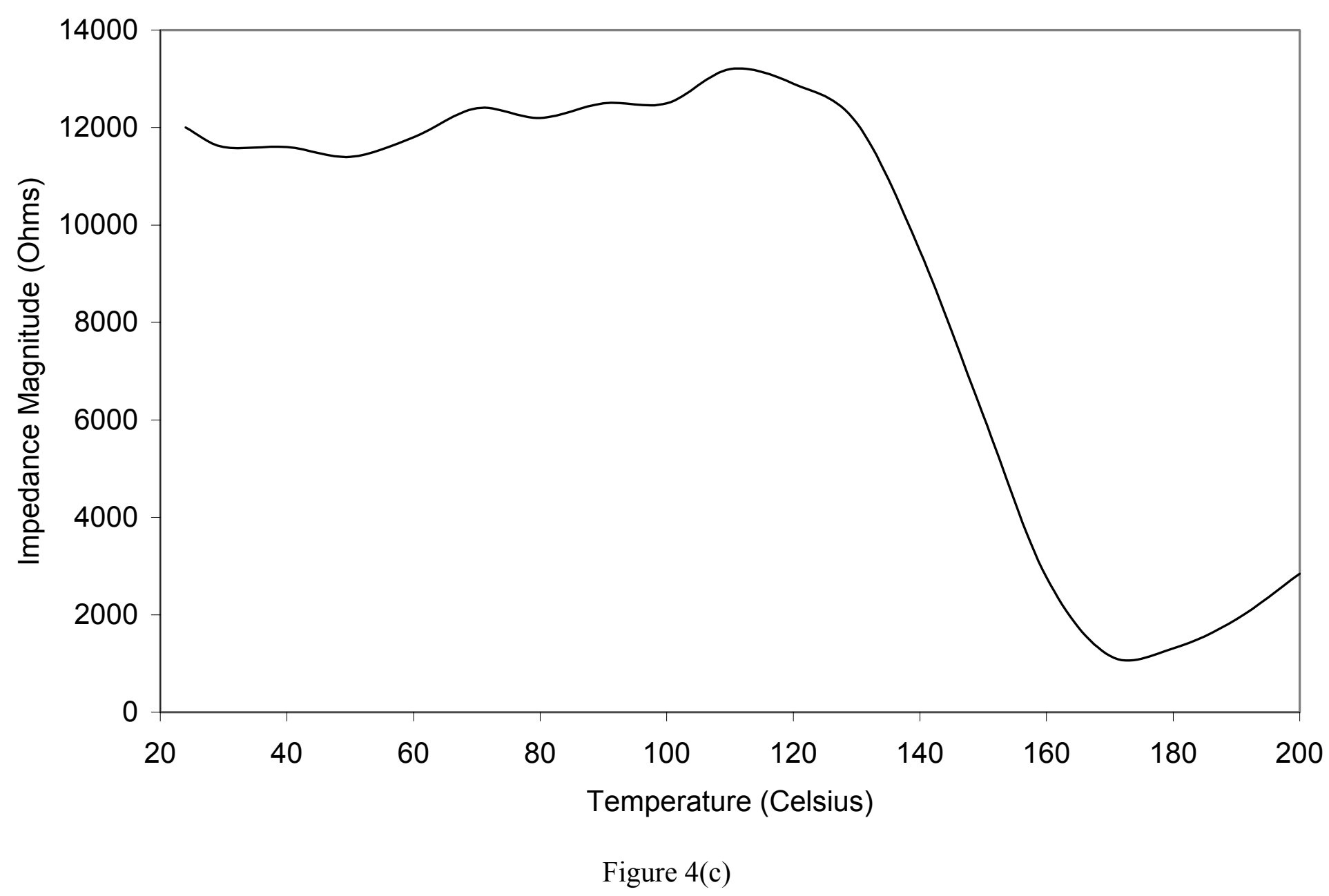




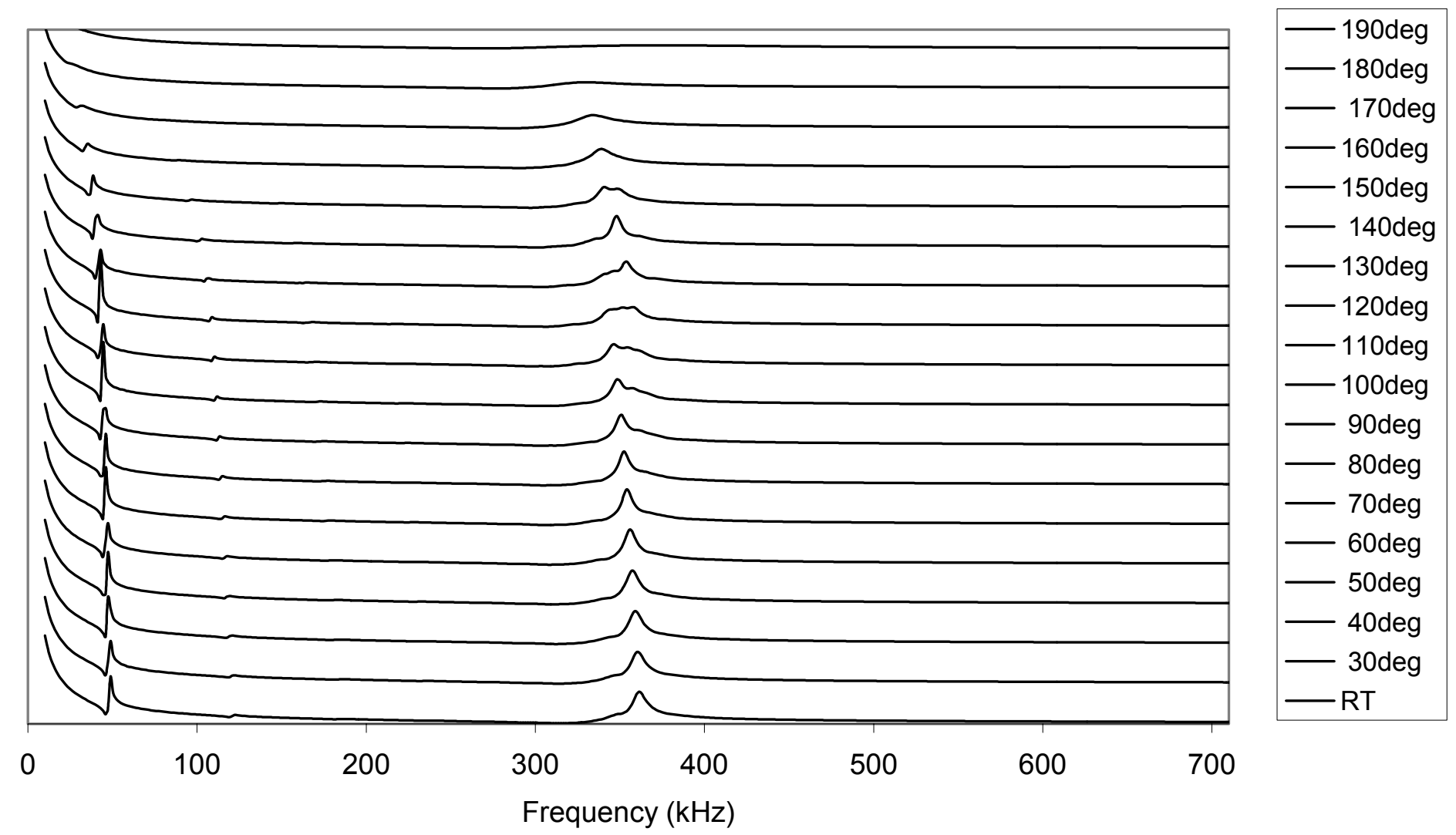

Figure 5 


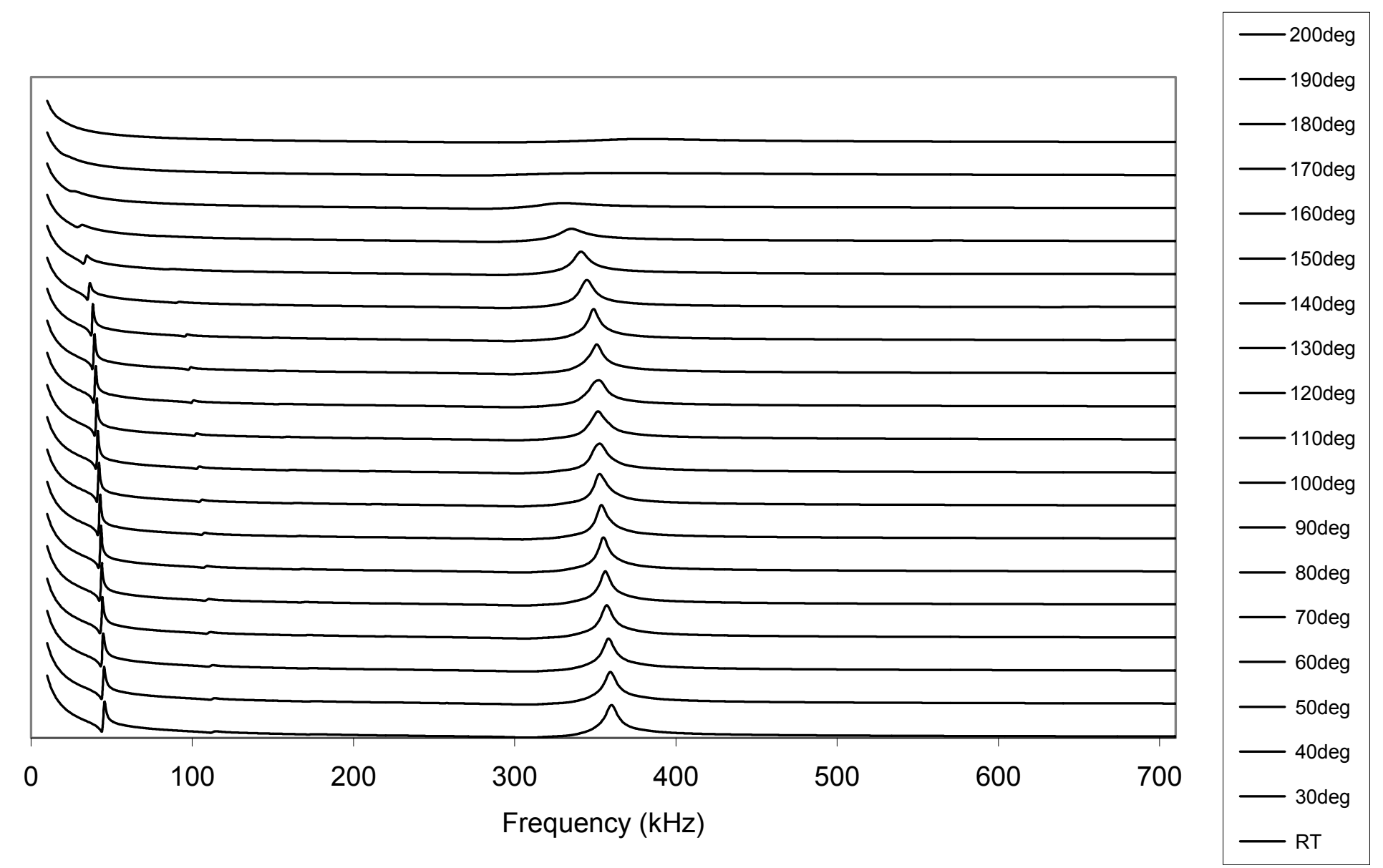

Figure 6 


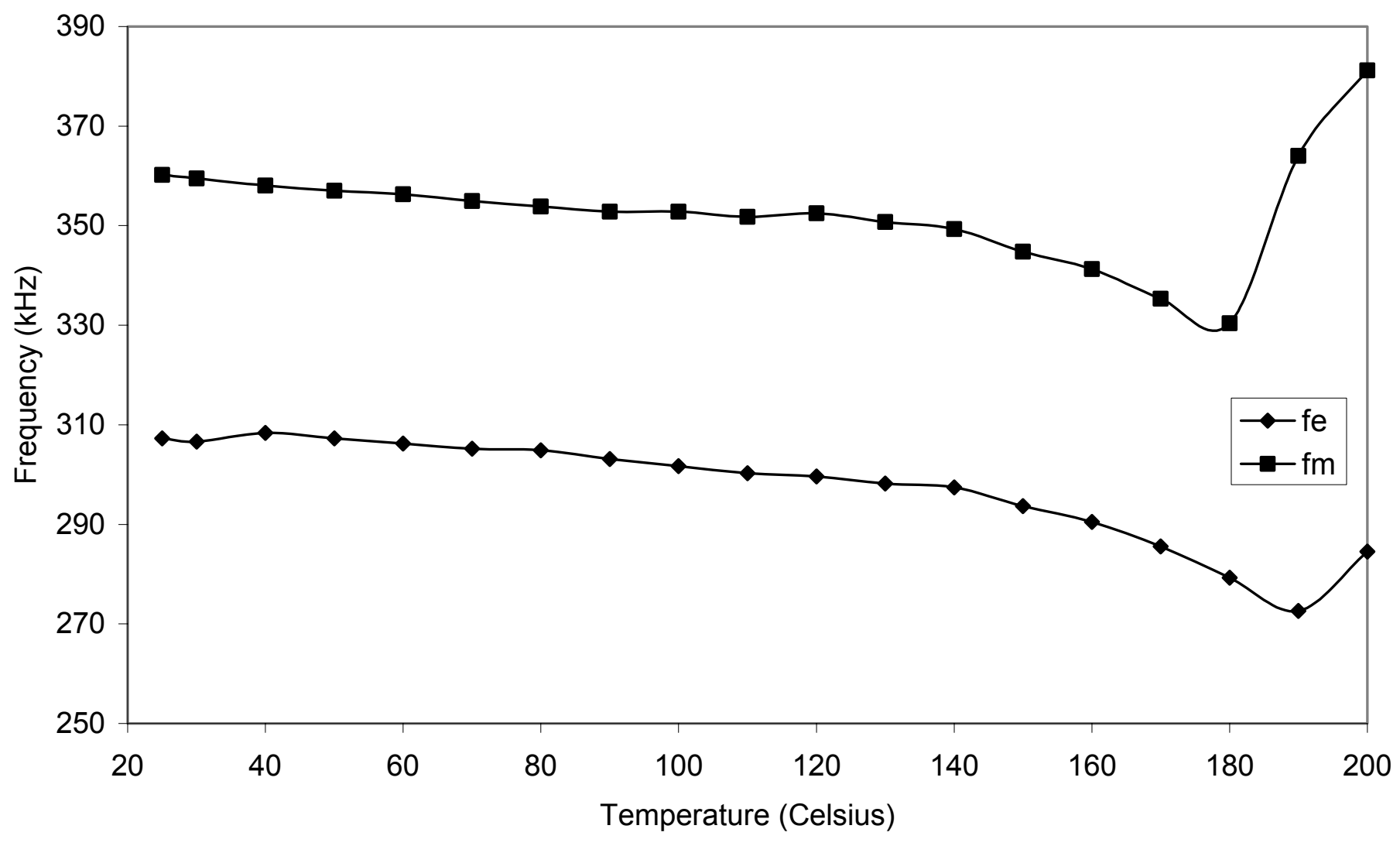

Figure 7(a) 


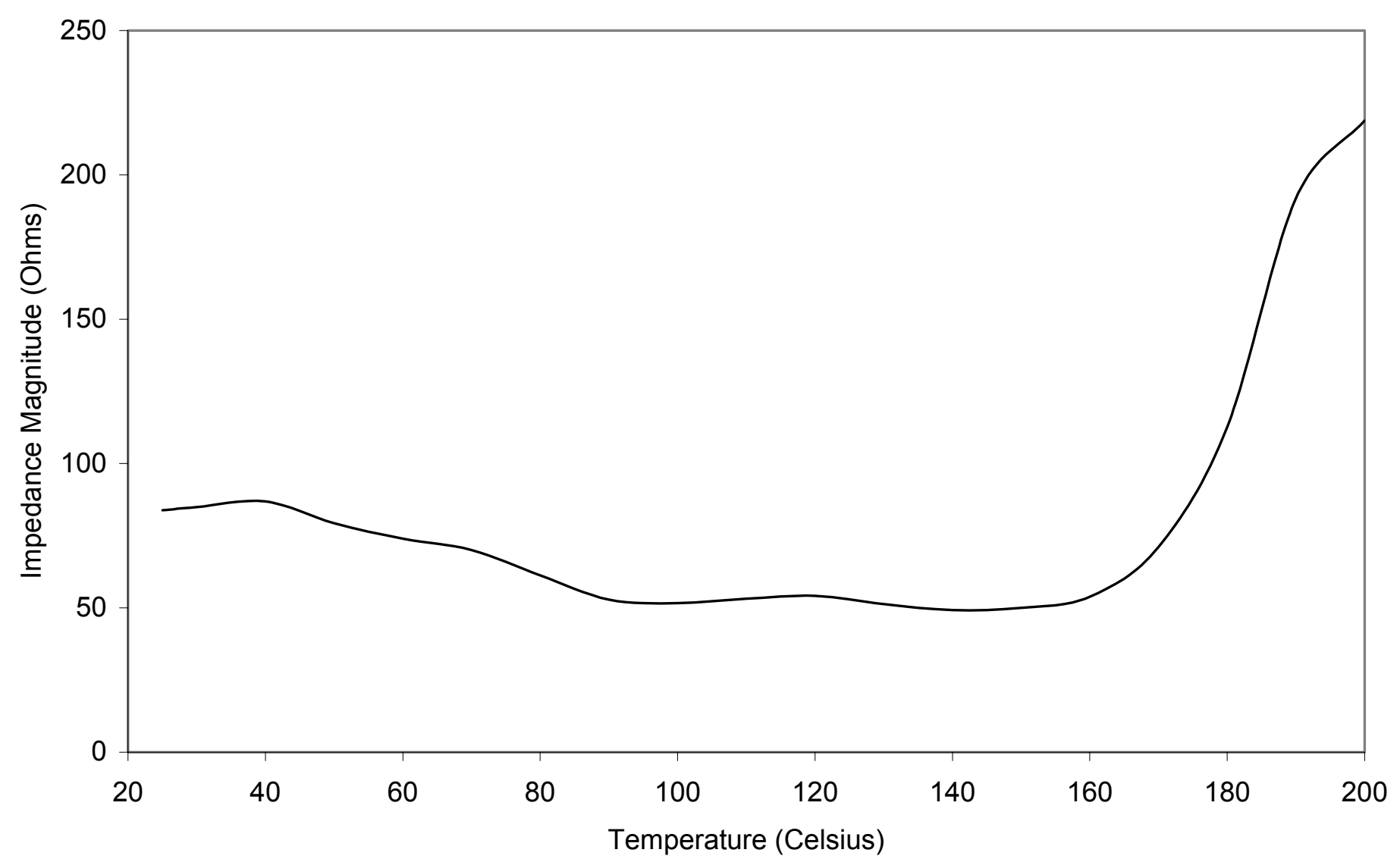

Figure 7(b) 


\section{Page 43 of 56}

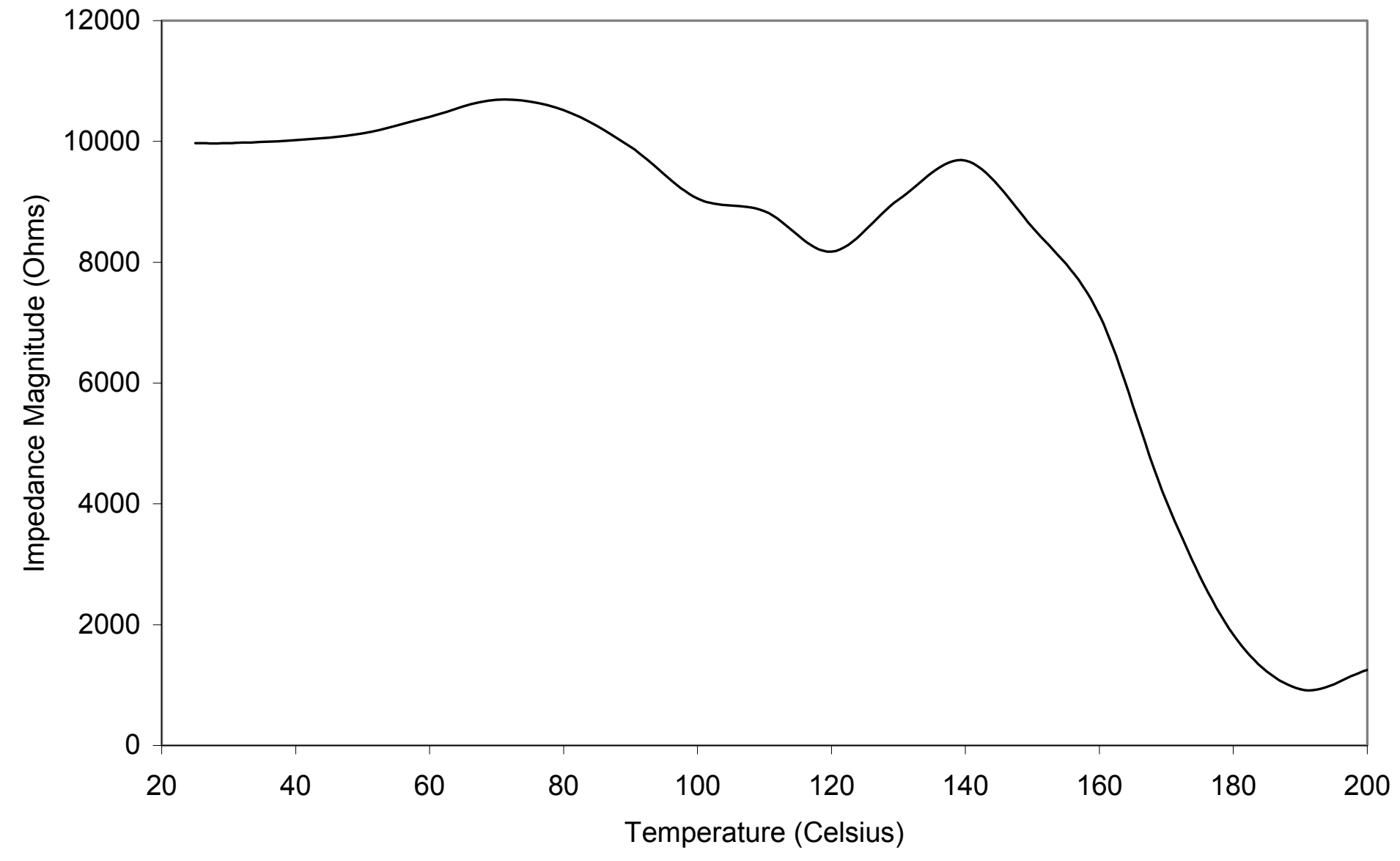

Figure 7(c) 


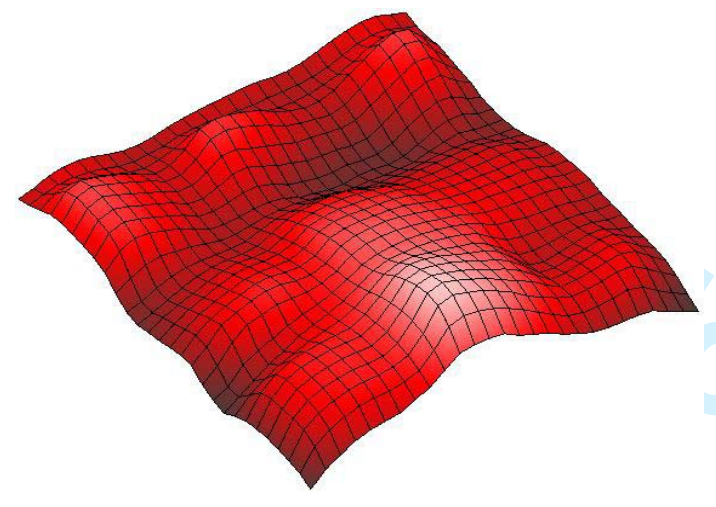

(a)

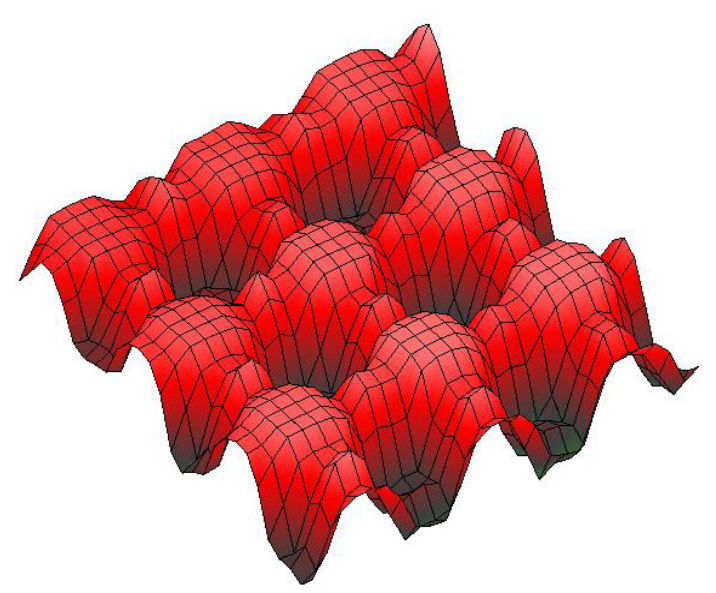

(c)

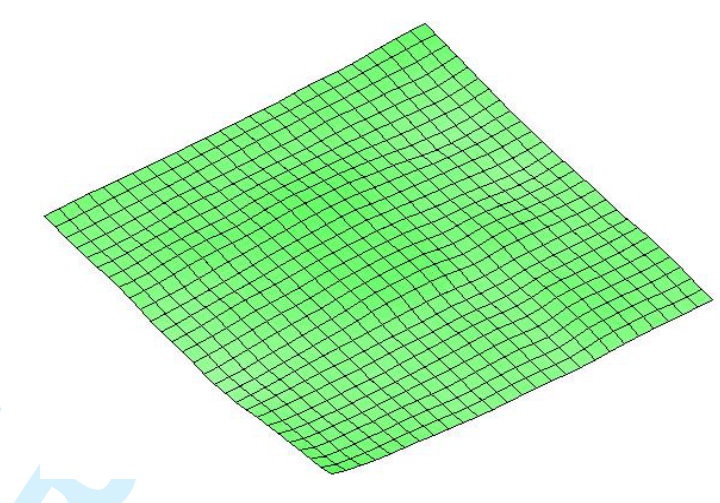

(b)



(d)

Figure 8 


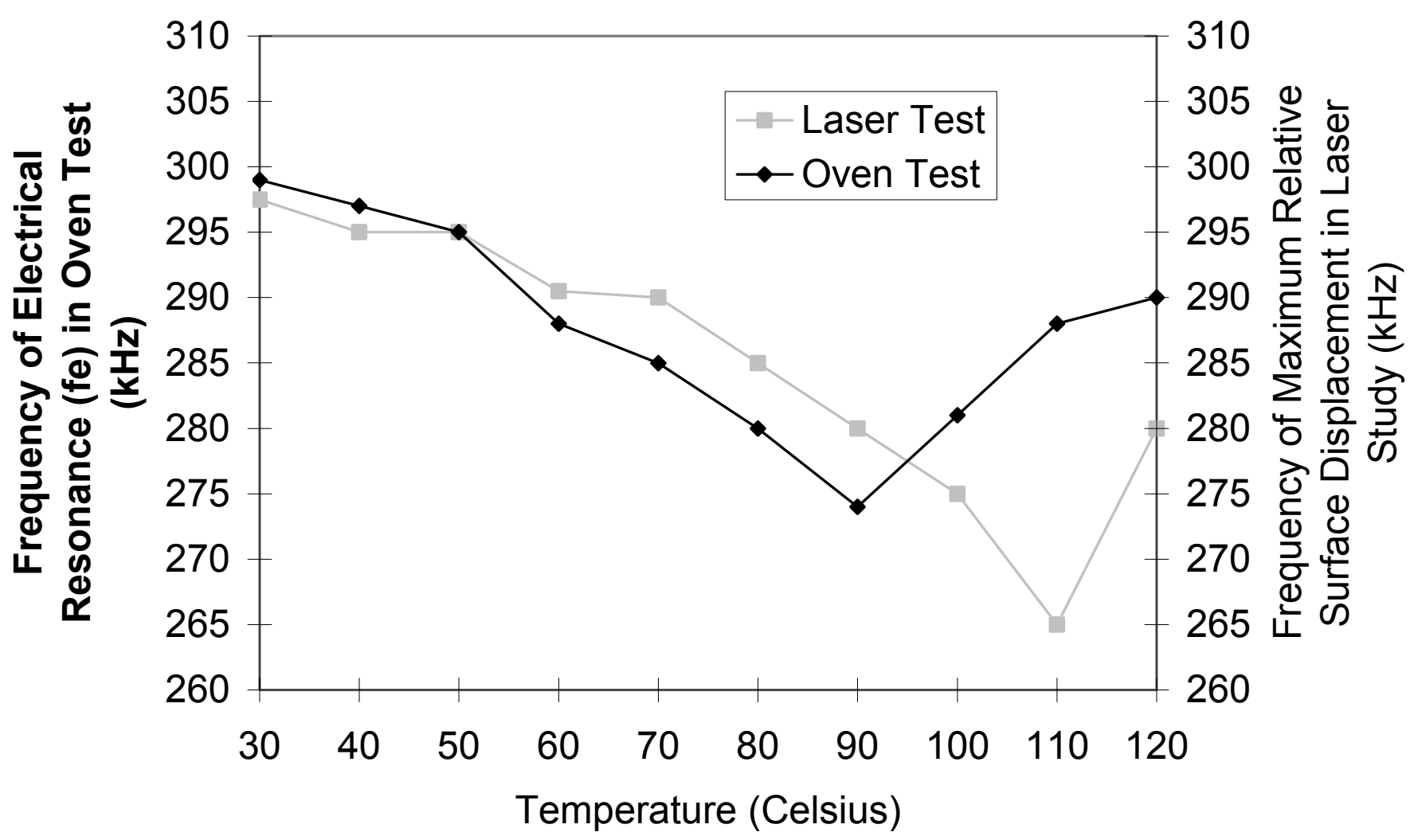

Figure 9(a) 


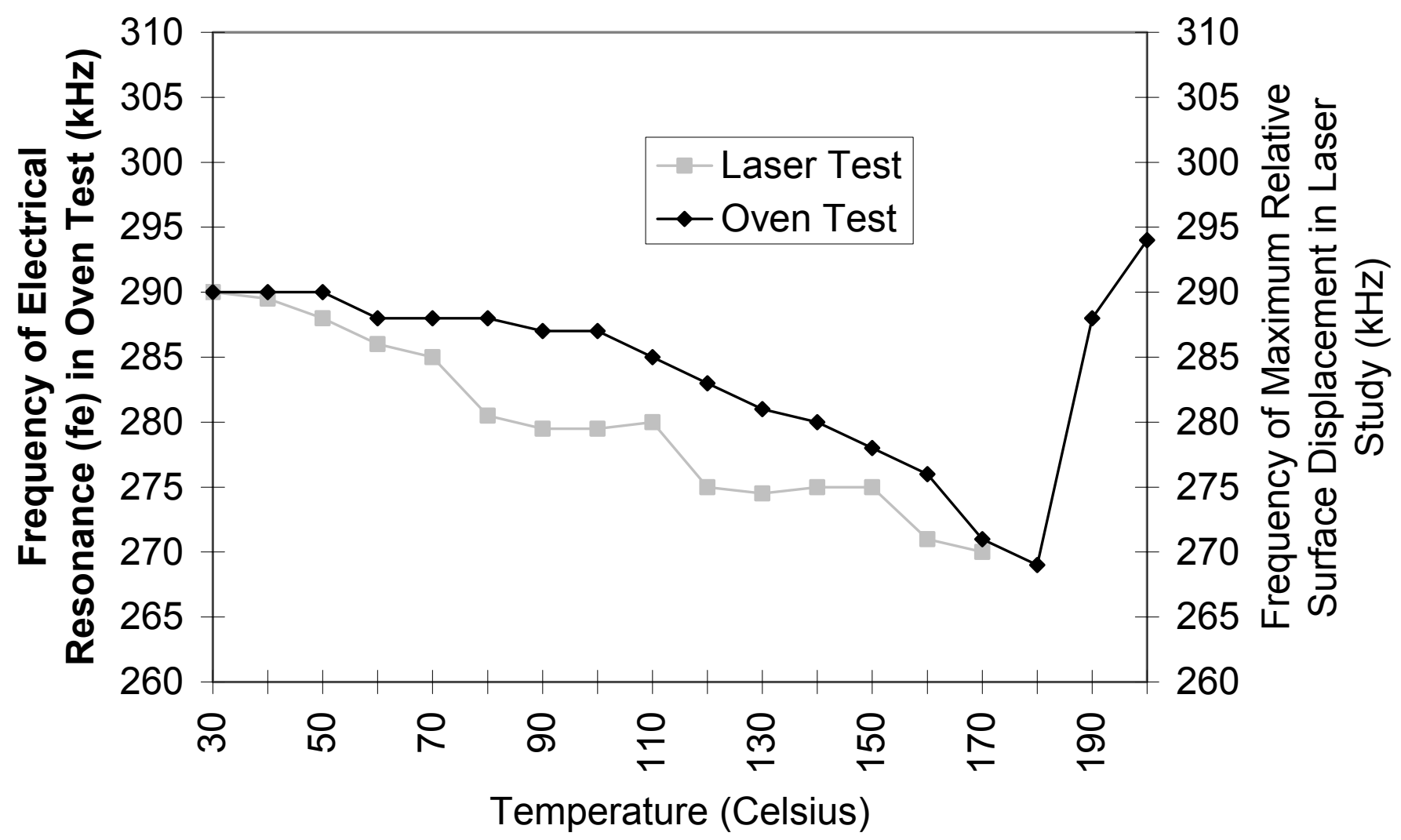

Figure 9(b) 


\section{Page 47 of 56}

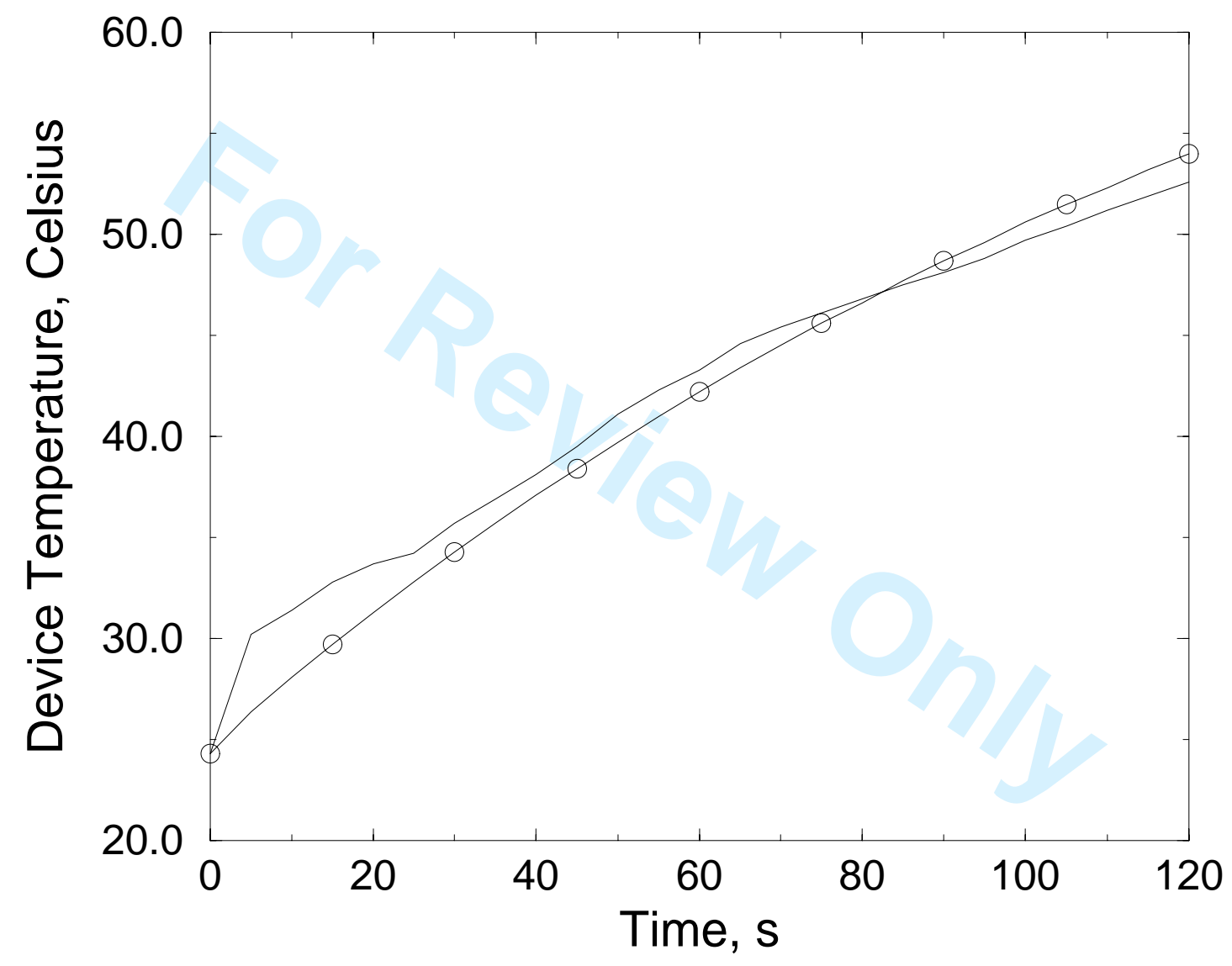

Figure 10(a) 


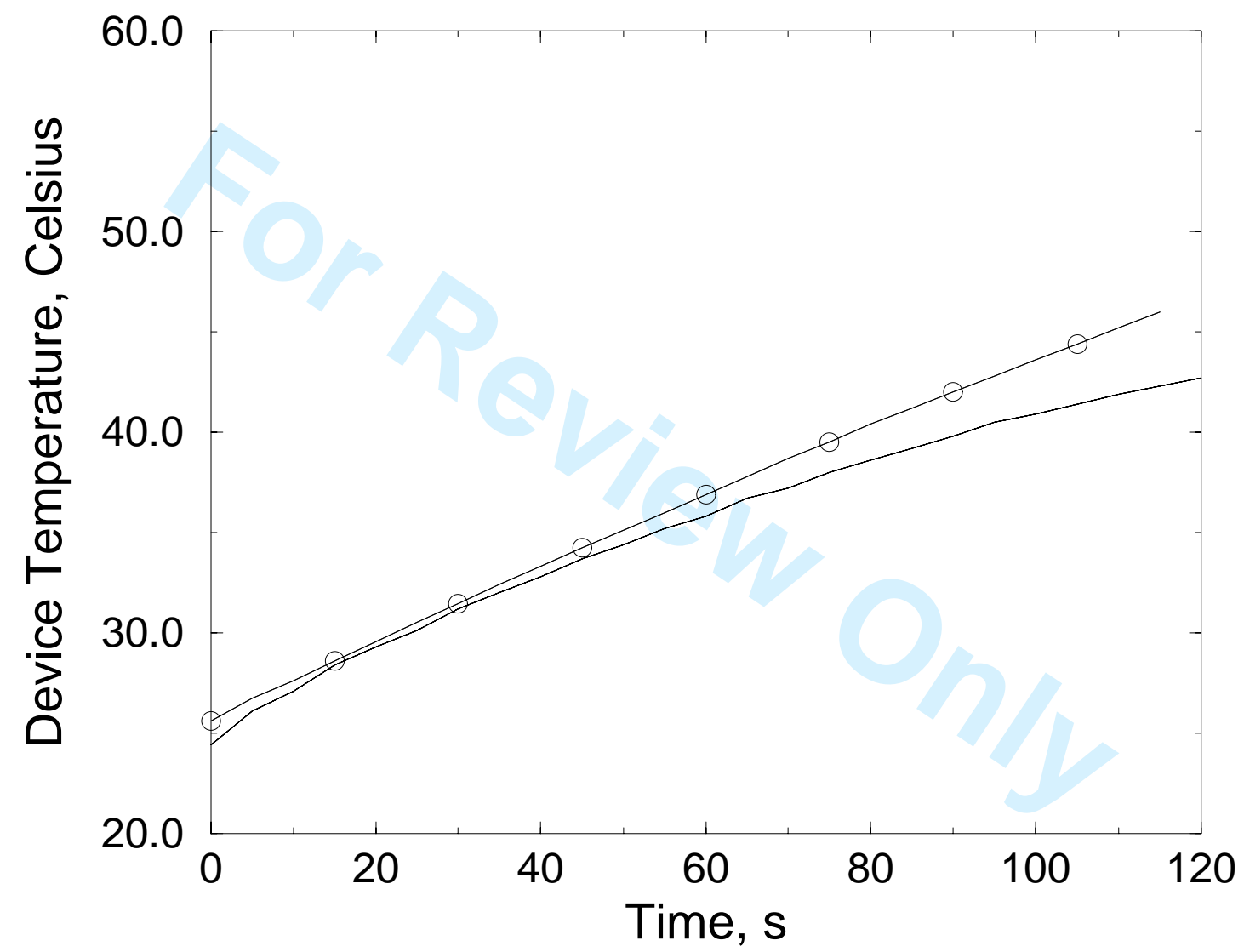

Figure 10(b) 


\section{Page 49 of 56}

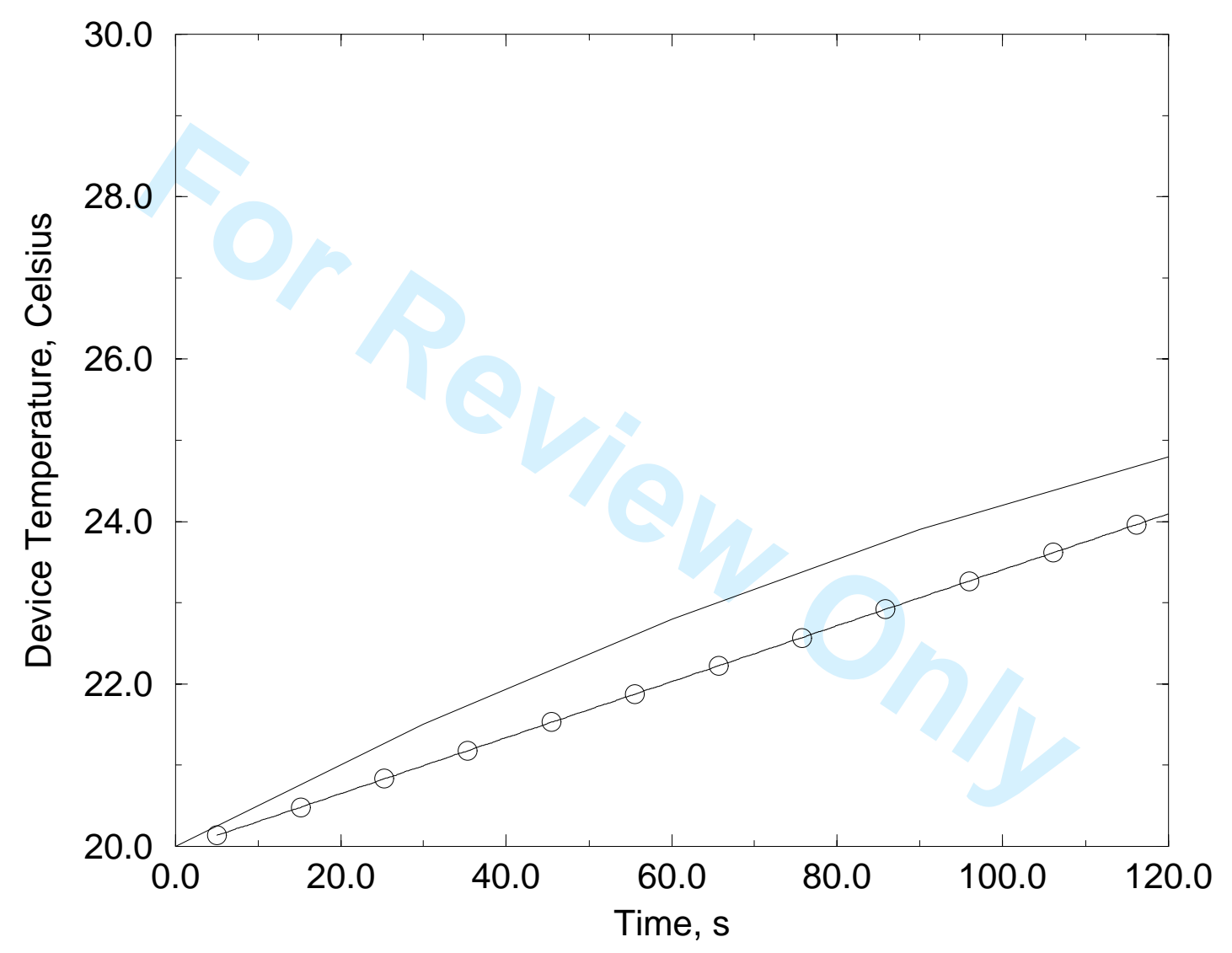

Figure 11(a) 


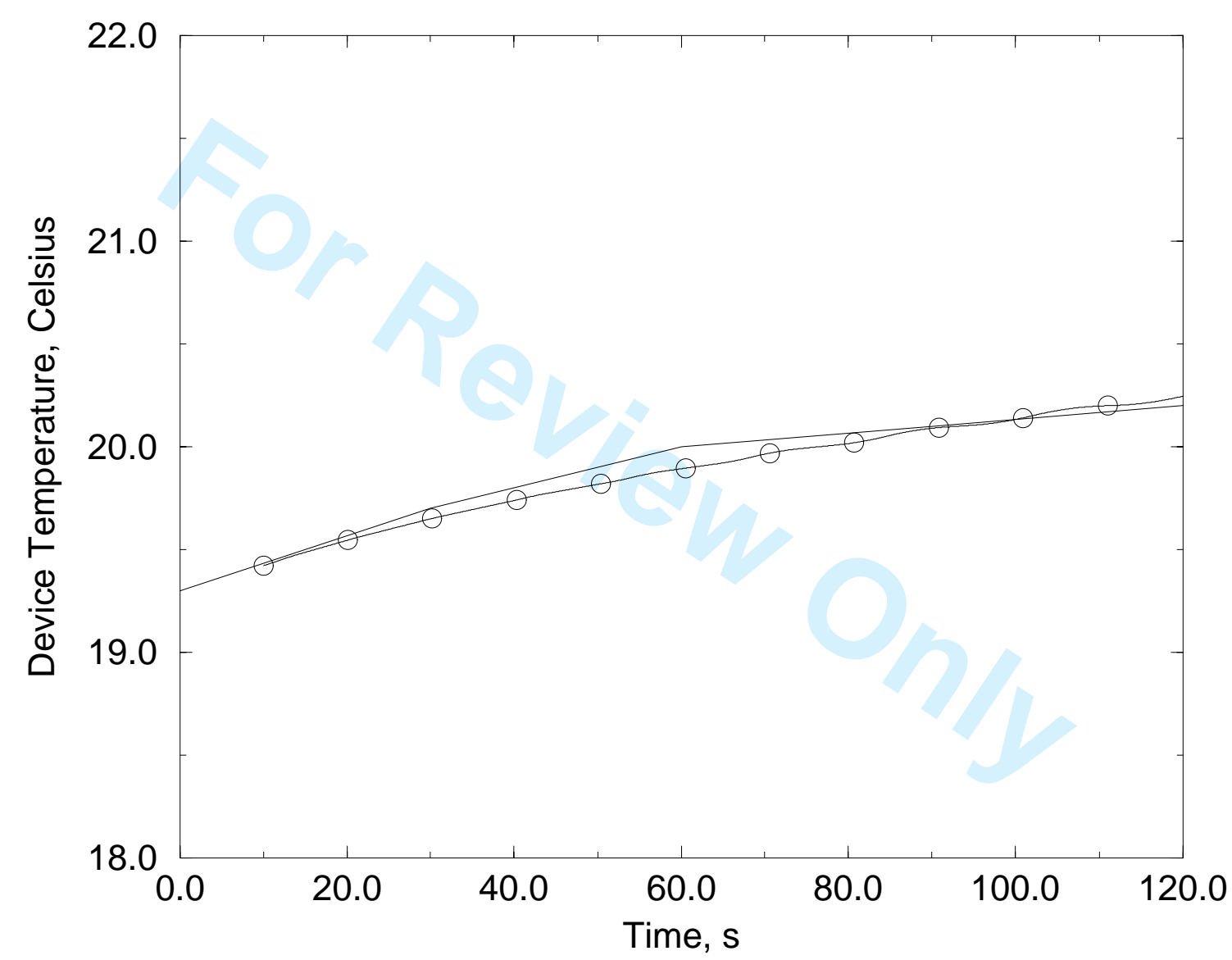

Figure 11(b) 


\section{Page 51 of 56}

1
2
3
4
5
6
7
8
9
10
11
12
13
14
15
16
17
18
19
20
21
22
23
24
25
26
27
28
29
30
31
32
33
34
35
36
37
38
39
40
41
42
43
44
45
46
47

.

.

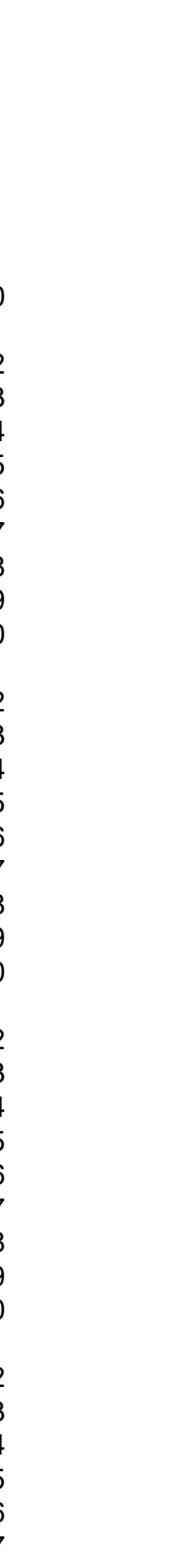

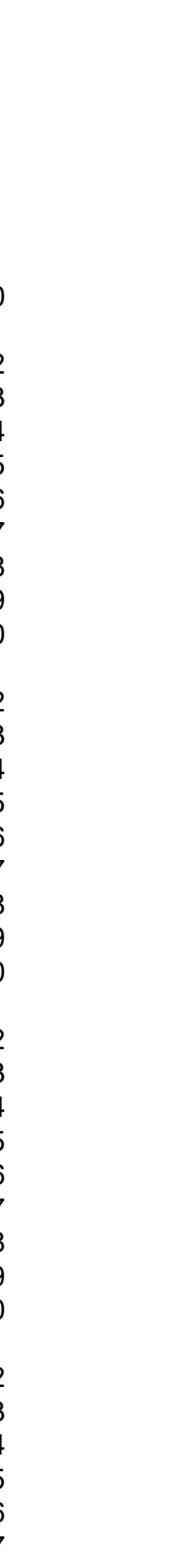

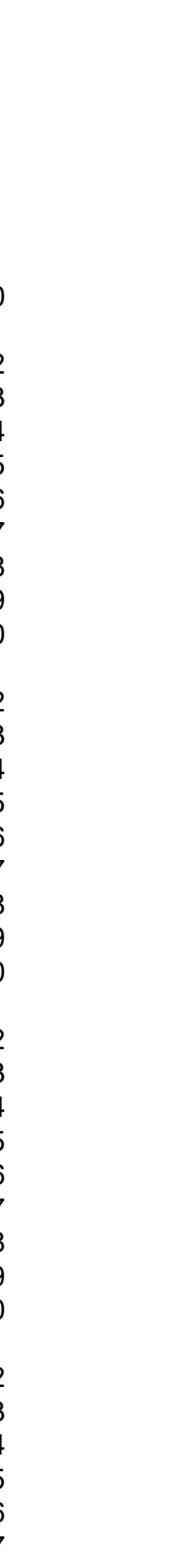

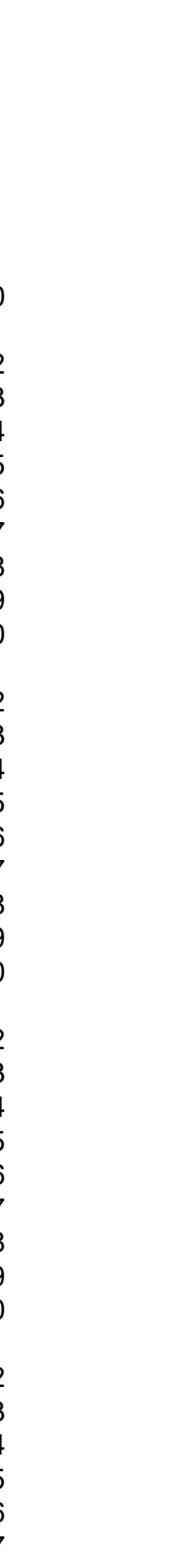




\title{
Figure Captions
}

\author{
Figure 1 Variation in Electrical Impedance Characteristic as a Function of Temperature \\ for (a) Device Al (b) on Device B (c) on Device C
}

\begin{abstract}
Figure 2 Effect of Temperature on Device Al for (a) the thickness mode electrical $\left(f_{e}\right)$ and mechanical $\left(f_{m}\right)$ resonance frequencies, (b) the impedance magnitude at $f_{e}$ and $(c)$ the impedance magnitude at $f_{m}$
\end{abstract}

Figure 3 Variation in Electrical Impedance Characteristic as a Function of Temperature for Device D

Figure 4 Effect of Temperature on Device D for (a) the thickness mode electrical $\left(f_{e}\right)$ and mechanical $\left(f_{m}\right)$ resonance frequencies, (b) the impedance magnitude at $f_{e}$ and $(c)$ the impedance magnitude at $f_{m}$

Figure 5 Variation in Electrical Impedance Characteristic as a Function of Temperature for Device $G$

Figure 6 Variation in Electrical Impedance Characteristic as a Function of Temperature for Device $H$ 
Figure 7 Effect of Temperature on Device H for (a) the thickness mode electrical $\left(f_{e}\right)$ and mechanical $\left(f_{m}\right)$ resonance frequencies, (b) the impedance magnitude at $f_{e}$ and (c) the impedance magnitude at $f_{m}$

Figure 8 The Effect of increasing device Temperature on the Surface Displacement Profiles of Device A Measured at $280 \mathrm{kHz}$ (a) Displacement Amplitude $28^{\circ} \mathrm{C}$, (b) Displacement Phase $28^{\circ} \mathrm{C}$, (c) Displacement Amplitude $100^{\circ} \mathrm{C}$ and (d) Displacement Phase $100^{\circ} \mathrm{C}$

Figure 9 Comparison of the Variation in the Frequency of the Impedance Minimum as a Function of Temperature Measured from the Electrical Impedance Characteristic and the Frequency of Maximum Surface Displacement for (a) device A2 and (b) device D

Figure 10 Theoretical and Experimental Temperature Response of (a) Device A and (b) Device B; (-) experiment, (O) theory

Figure 11 Theoretical and Experimental Temperature Response of Device G (a) air-loaded case (b) water-loaded case; (-) experiment, (O) theory 


\begin{tabular}{|c|c|c|c|c|}
\hline Code & Material Type & $\begin{array}{c}\text { Commercial } \\
\text { Product }\end{array}$ & $\begin{array}{c}\text { Polymeric } \\
\text { Components }\end{array}$ & Particulate Filler \\
\hline $\mathbf{A}$ & Standard (Hard) & Huntsman Araldite & $\begin{array}{c}\text { CY1301/HY } 1300 \\
(3: 1)\end{array}$ & Unfilled \\
\hline B & $\begin{array}{l}\text { Standard } \\
\text { (Medium) }\end{array}$ & Huntsman Araldite & CY221/HY956 (5:1) & Unfilled \\
\hline $\mathrm{C}$ & Standard (Soft) & Huntsman Araldite & CY208/HY956 (8:1) & Unfilled \\
\hline D & High $T_{g}$ & Huntsman Araldite & $\begin{array}{c}\text { MY750/HY906/DY06 } \\
2(10: 9: 0.2) \text { Cure } 1 \mathrm{hr} \\
100^{\circ} \mathrm{C}, 2 \mathrm{hr} 180^{\circ} \mathrm{C}\end{array}$ & Unfilled \\
\hline $\mathbf{E}$ & $\begin{array}{c}\text { Thermally } \\
\text { Conductive } \\
\text { Particles }\end{array}$ & $\begin{array}{c}\text { Emerson and } \\
\text { Cuming/Stycast }\end{array}$ & $\begin{array}{c}2651-40 / 8 \% \text { Catalyst } 9 \\
\text { Cure } 2 \text { hrs } 65^{\circ} \mathrm{C}\end{array}$ & Mica \\
\hline $\mathbf{F}$ & $\begin{array}{l}\text { Thermally } \\
\text { Conductive } \\
\text { Particles }\end{array}$ & $\begin{array}{c}\text { Emerson and } \\
\text { Cuming/Stycast }\end{array}$ & $\begin{array}{c}2850-\mathrm{FT} / 3 \% \text { Catalyst } 9 \\
\text { Cure } 2 \text { hrs } 65^{\circ} \mathrm{C}\end{array}$ & Aluminium Oxide \\
\hline $\mathbf{G}$ & $\begin{array}{l}\text { Thermally } \\
\text { Conductive } \\
\text { Particles }\end{array}$ & & $\begin{array}{c}\text { MY750/HY906/DY06 } \\
2(10: 9: 0.2) \text { Cure } 1 \mathrm{hr} \\
100^{\circ} \mathrm{C}, 2 \mathrm{hr} 180^{\circ} \mathrm{C}\end{array}$ & $\begin{array}{c}\text { Aluminium Oxide, } \\
\text { 30vol\%, Aldrich } \\
\text { 26,549-7, 99.7\%, } \\
<10 \mu \mathrm{m}\end{array}$ \\
\hline H & $\begin{array}{l}\text { Thermally } \\
\text { Conductive } \\
\text { Particles }\end{array}$ & & $\begin{array}{c}\text { MY750/HY906/DY06 } \\
2(10: 9: 0.2) \text { Cure } 1 \mathrm{hr} \\
100^{\circ} \mathrm{C}, 2 \mathrm{hr} 180^{\circ} \mathrm{C}\end{array}$ & $\begin{array}{c}\text { Aluminium } \\
\text { Nitride, } 24 \mathrm{vol} \% \text {, } \\
\text { Aldrich } 24,190-3 \text {, } \\
98+\%,<10 \mu \mathrm{m}\end{array}$ \\
\hline
\end{tabular}

Table 1

\begin{tabular}{|l|c|c|c|c|c|c|c|c|}
\hline Polymer & A & B & C & D & E & F & G & H \\
\hline Vl (m/s) & 2513 & 2364 & 1914 & 2342 & 2925 & 3377 & 2813 & 2636 \\
\hline Vs (m/s) & 1175 & 1065 & 809 & 1094 & 1494 & 1780 & 1464 & 1345 \\
\hline$\rho\left(\mathbf{k g} / \mathbf{m}^{\mathbf{3}}\right)$ & 1149 & 1134 & 1165 & 1150 & 1503 & 2292 & 2007 & 1673 \\
\hline $\boldsymbol{E}$ & 0.360 & 0.373 & 0.391 & 0.360 & 0.323 & 0.308 & 0.314 & 0.324 \\
\hline $\mathbf{E}(\mathbf{G P a})$ & 4.28 & 3.53 & 2.12 & 3.75 & 8.88 & 18.99 & 11.3 & 8.01 \\
\hline $\mathbf{B}(\mathbf{G P a})$ & 5.10 & 4.62 & 3.25 & 4.47 & 8.38 & 16.45 & 10.14 & 7.60 \\
\hline $\mathbf{G}(\mathbf{G P a})$ & 1.57 & 1.28 & 0.76 & 1.38 & 3.35 & 7.26 & 4.30 & 3.03 \\
\hline $\mathbf{Z} \mathbf{( M R a y l )}$ & 2.86 & 2.68 & 2.23 & 2.69 & 4.40 & 7.74 & 5.65 & 4.41 \\
\hline $\boldsymbol{\alpha}_{\mathbf{l}}(\mathbf{d B} / \mathbf{m})$ & 139 & 208 & 1008 & 174 & 176 & 96 & 174 & 174 \\
\hline $\boldsymbol{\alpha}_{\mathbf{s}}(\mathbf{d B} / \mathbf{m})$ & 356 & 2319 & 5090 & 243 & 363 & 252 & 400 & 382 \\
\hline
\end{tabular}

Table 2 


\begin{tabular}{|c|c|c|c|c|c|c|c|c|}
\hline Polymer & $\mathbf{A}$ & B & $\mathbf{C}$ & D & $\mathbf{E}$ & $\mathbf{F}$ & $\mathbf{G}$ & $\mathbf{H}$ \\
\hline $\begin{array}{l}\mathrm{Cp} @ 25^{\circ} \mathrm{C} \\
(\mathrm{kJ} / \mathrm{kgK})\end{array}$ & 1.35 & 1.97 & 1.77 & 1.25 & 1.14 & 0.92 & 0.62 & 0.84 \\
\hline $\begin{array}{l}\tan \delta \\
\max \left({ }^{\circ} \mathrm{C}\right)\end{array}$ & 60 & 40 & 6 & 151 & 87 & 84 & 154 & 145 \\
\hline $\begin{array}{l}\propto @ 25^{\circ} \mathrm{C} \\
10^{-3}\left(\mathrm{~cm}^{2} / \mathrm{s}\right)\end{array}$ & 1.42 & & & $\begin{array}{l}1.04 \\
\mathbf{1 . 0 5}\end{array}$ & $\begin{array}{r}2.92 \\
\mathbf{2 . 3 3}\end{array}$ & $\begin{array}{l}6.45 \\
\mathbf{5 . 0 0}\end{array}$ & 3.05 & 2.95 \\
\hline k (W/mK) & $0.22^{10}$ & $v$ & & $0.15^{10}$ & $\begin{array}{l}0.5^{11} \\
0.38\end{array}$ & $\begin{array}{l}1.36^{11} \\
\mathbf{1 . 0 5}\end{array}$ & 0.38 & 0.41 \\
\hline
\end{tabular}

\section{Table 3}

\begin{tabular}{|l|c|c|c|c|c|c|c|c|c|}
\hline Device & A1 & A2 & B & C & D & E & F & G & H \\
\hline Polymer & A & A & B & C & D & E & F & G & H \\
\hline Kerf (mm) & 0.66 & 0.63 & 0.61 & 0.61 & 0.63 & 0.63 & 0.61 & 0.61 & 0.66 \\
\hline Pitch (mm) & 1.71 & 1.73 & 1.71 & 1.71 & 1.73 & 1.68 & 1.71 & 1.68 & 1.76 \\
\hline $\begin{array}{l}\text { Thickness } \\
(\mathbf{m m})\end{array}$ & 5.00 & 4.87 & 4.34 & 4.53 & 5.07 & 3.57 & 4.29 & 4.89 & 4.92 \\
\hline fe (kHz) & 297 & 299 & 328 & 308 & 290 & 437 & 388 & 313 & 307 \\
\hline fm (kHz) & 358 & 364 & 404 & 401 & 346 & 513 & 435 & 360 & 360 \\
\hline
\end{tabular}

Table 4 


\section{Table Captions}

Table 1 Polymeric Passive Phase Materials Investigated

Table 2 Acoustic Characterisation $(500 \mathrm{kHz})$

Table 3 Thermal Behaviour where Italic is Calculated value and Bold is Measured Experimental value

Table 4 Constructional Parameters of the Nine Piezoelectric Composite Devices to be Studied 